(2) Open Access Full Text Article

REVIEW

\title{
Preparation, characterization, and potential application of chitosan, chitosan derivatives, and chitosan metal nanoparticles in pharmaceutical drug delivery
}

\author{
This article was published in the following Dove Press journal: \\ Drug Design, Development and Therapy \\ 28 January 2016 \\ Number of times this article has been viewed
}

\author{
Tarek A Ahmed ${ }^{1,2}$ \\ Bader M Aljaeid' \\ 'Department of Pharmaceutics \\ and Industrial Pharmacy, Faculty of \\ Pharmacy, King Abdulaziz University, \\ Jeddah, Kingdom of Saudi Arabia; \\ ${ }^{2}$ Department of Pharmaceutics \\ and Industrial Pharmacy, Faculty \\ of Pharmacy, Al-Azhar University, \\ Cairo, Egypt
}

\begin{abstract}
Naturally occurring polymers, particularly of the polysaccharide type, have been used pharmaceutically for the delivery of a wide variety of therapeutic agents. Chitosan, the second abundant naturally occurring polysaccharide next to cellulose, is a biocompatible and biodegradable mucoadhesive polymer that has been extensively used in the preparation of microas well as nanoparticles. The prepared particles have been exploited as a potential carrier for different therapeutic agents such as peptides, proteins, vaccines, DNA, and drugs for parenteral and nonparenteral administration. Therapeutic agent-loaded chitosan micro- or nanoparticles were found to be more stable, permeable, and bioactive. In this review, we are highlighting the different methods of preparation and characterization of chitosan micro- and nanoparticles, while reviewing the pharmaceutical applications of these particles in drug delivery. Moreover, the roles of chitosan derivatives and chitosan metal nanoparticles in drug delivery have been illustrated. Keywords: nanoparticles, microparticles, preparation, characterization, pharmaceutical application
\end{abstract}

\section{Introduction}

Drug delivery is a general term that refers to formulation and administration of a pharmacologically active compound for the purpose of providing an efficient drug plasma concentration, as well as bringing the drug to the specific site of action. Different strategies have been employed to overcome some drug stability issues in the gastrointestinal tract (GIT), control the drug release, enhance the transmucosal absorption, as well as get the drug into its site of action. Microfabrication is a technique that creates materials in the micrometer scale feature and has been reported to significantly improve diagnosis and biomedical applications. Modification of the material shape, surface characteristics, and release kinetics is a consequence of this micronization. ${ }^{1}$ Nanotechnology has been utilized as one of these strategies in the development of novel drug delivery systems through entrapment of the drug in nanoparticulate systems. ${ }^{2}$ In general, the potential applications of nanotechnology render this field an area of interest to many researchers and scientists. These applications have covered different scientific areas that extend from electronics to cosmetics. ${ }^{3-5}$

Polymers obtained from natural origins have been extensively employed not only in the food industry but also in pharmaceutical technology. Polysaccharide polymers have emerged as being one of these because they are less toxic, biocompatible, and biodegradable. ${ }^{6,7}$ Incorporation of the therapeutic agent into a polymeric matrix,
Correspondence: Tarek A Ahmed Department of Pharmaceutics and Industrial Pharmacy, Faculty of Pharmacy, King Abdulaziz University, PO Box 80200 , Jeddah 21589, Kingdom of Saudi Arabia Tel +966599828003

Email dr_tarek_nour@yahoo.com 
particularly of a natural origin, might potentiate the protection of the biologically active compound from degradation, control drug release, improve absorption, enhance the therapeutic effect, and lead to the consequential decrease in the frequency of administration. Chitosan, alginate, and carrageenan are the most commonly used polysaccharide polymers in various pharmaceutical applications. ${ }^{6-12}$ Chitosan is a polymer of interest that has been widely used for delivery of different therapeutic agents, particularly those based on chitosan micro- and nanoparticles, owing to its unique properties. Preparation of mucoadhesive formulations, enhancing the dissolution rate especially for poorly watersoluble drugs, utilization in drug targeting, and improvement of protein absorption are common therapeutic applications of this naturally occurring polymer. ${ }^{13}$

In this review, the importance of chitosan, as a naturally occurring polysaccharide polymer, and its derivatives in drug delivery are illustrated. The different methods of preparation and characterization of chitosan micro- and nanoparticles are addressed. The usefulness of these particles in parenteral and nonparenteral drug delivery is demonstrated. Finally, a very specific application of chitosan in the preparation of metal-based nanoparticles is clarified, establishing the advantages of chitosan metal nanoparticles over the metal nanoparticles.

\section{Chitosan as a polymeric drug carrier}

Chitosan is a molecule with a carbohydrate backbone structure similar to cellulose, which consists of two types of repeating units, $N$-acetyl-D-glucosamine and D-glucosamine, linked by (1-4)- $\beta$-glycosidic linkage. ${ }^{14}$ It is a biopolyaminosaccharide cationic polymer that is obtained from chitin by alkaline deacetylation and characterized by the presence of a large numbers of amino groups on its chain (Figure 1). Although chitosan is obtained from chitin, the applications of the latter compared to chitosan are limited because it is chemically inert. A common method for chitosan synthesis is the deacetylation of chitin, usually derived from the

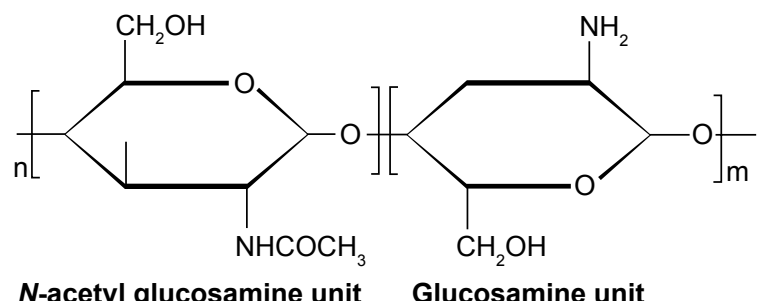

$\mathrm{N}$-acetyl glucosamine unit Glucosamine unit

Figure I Chemical structure of chitosan showing the repeating subunits. shells of shrimp and other sea crustaceans, using excess aqueous sodium hydroxide solution as a reagent. Chitosan is insoluble in water but soluble in dilute acidic solutions of acetic, citric, and tartaric but not phosphoric or sulfuric at $\mathrm{pH}$ less than $6.5 .{ }^{15}$ In dilute aqueous acidic solution, the free amino groups of chitosan glucosamine units that have an apparent $\mathrm{p} K_{\mathrm{a}}$ of 6.5 undergo protonation and convert into the ionizable soluble $\mathrm{R}-\mathrm{NH}_{3}{ }^{+}$form. ${ }^{16}$ Usually, dilute aqueous acetic acid solution in concentrations $1 \%-3 \%$ is used to make a soluble chitosan solution. Chitosan is available in low and high molecular weights, ranging between 3,800 and 20,000 Da, and with different grades of deacetylation degree. The molecular weight and degree of deacetylation strongly affect chitosan properties, particularly during the development of micro- and nanoparticles. Chitosan is precipitated with polyanions and in alkaline solutions. Although chitosan has revealed some therapeutic activity such as lowering of cholesterol, ${ }^{17}$ wound healing, ${ }^{18}$ antiulcer, ${ }^{19}$ and antimicrobial effects, ${ }^{20}$ it is widely used as a polymeric drug carrier owing to its biocompatibility, biodegradability, and nontoxic characters.

Chitosan is characterized by mucoadhesive properties owing to the electrostatic interaction between the positive charge on ionizable $\mathrm{R}-\mathrm{NH}_{3}{ }^{+}$group and the negative charge on the mucosal surfaces. ${ }^{21}$ The interaction of the protonated amine groups with the cell membrane results in a reversible structural reorganization in the protein-associated tight junctions, which is followed by opening of these tight junctions. Sinha et $\mathrm{al}^{22}$ showed that the molecular weight, strong electrostatic interaction, chitosan chain flexibility, possibility of hydrogen bond formation due to availability of bonding groups such as carboxylic and hydroxyl groups, and ease of spreading into the mucus owing to surface energy properties are factors that attribute to this character. Another advantage that makes chitosan superior to other polysaccharide polymers is the ease of chemical modifications in the structure, especially in the C-2 position, which provide derivatives with different characteristics, with potential use in different applications. ${ }^{23}$ Pharmaceutically, chitosan-based polymeric drug carriers have been successfully utilized in the delivery of anticancer agents, proteins/peptides, growth factors, antibiotics, anti-inflammatory and other drugs, as well as a strategy in both vaccine delivery and gene therapy. ${ }^{24,25}$ In addition to the mucoadhesive nature and ease of chemical modification, chitosan possesses properties such as biocompatibility, low toxicity, and biodegradability that make this polymer a good candidate for pharmaceutical formulations through 
several routes of administration, as will be illustrated in the following sections.

In general, the mucoadhesive nature, which increases the time of attachment at the absorption site, the easy availability of free amino group for cross-linking, ease of fabrication of polymeric particles without using hazardous solvents, the cationic nature that permits ionic cross-linking with multivalent anions, and finally the ability to control the release of the administered drug makes chitosan the polymer of choice for developing the polymeric particle.

\section{Chitosan derivatives}

Different chitosan derivatives have been synthesized and studied for their potential applications. Modification does not result in change of the chitosan fundamental skeleton but brings derivatives characterized by new or improved properties. These derivatives have been reported to increase the permeation of drugs, especially hydrophilic macromolecules, achieve colon targeting, protect acid sensitive drugs, enhance drug release in basic environment, and overcome the limited solubility of chitosan in neutral $\mathrm{pH} .{ }^{26,27}$ Various chemically modified chitosan derivatives have been produced through alteration in the chitosan amine or hydroxyl functional groups. Quaternized, thiolated, hydrophobic, and chemically grafted chitosan derivatives are types that have been reported to improve or impart new properties to chitosan.

Quaternary chitosan derivatives of the $N$-alkyl or quaternary ammonium types have been developed. These derivatives are characterized by their permanent cationic charge (resulting in increase of solubility of chitosan in water and keeping it soluble over a wide range of $\mathrm{pH}$ ) and their enhanced mucoadhesive and loaded drug penetration properties. $\mathrm{N}$-alkylated chitosan derivatives such as trimethyl, diethylmethyl, triethyl, and dimethyl ethyl chitosans are usually obtained by alkylation of the primary amine groups of chitosan with the suitable aldehyde in the presence of reducing agents. $N$-trimethyl chitosan (TMC) is synthesized by methylation of the chitosan amine groups with methyl iodide. ${ }^{28}$ The water solubility of TMC is highly dependent on the degree of methylation. ${ }^{29}$ An enhancement in the mucoadhesive and, hence, absorption even at neutral $\mathrm{pH}$ has been reported for soluble TMC. ${ }^{30-32}$ Quaternary ammonium chitosan derivatives such as $N$-(2-hydroxyl) propyl-3-trimethyl ammonium chitosan chloride (HTCC) has been produced by introducing a quaternary ammonium moiety such as glycidyl trimethyl ammonium to the chitosan amine groups, and that was used to formulate albumin-loaded chitosan derivative nanoparticles that showed a size range between 110 and $180 \mathrm{~nm}$ and more than $90 \%$ albumin encapsulation efficiency. ${ }^{33}$

Thiolated chitosans are obtained by modification of the chitosan amine groups with cystein, 2-iminothiolane, thiobutylamidine, or thioglycolic acid. The obtained modified chitosan derivatives exhibited improved oral as well as nasal mucoadhesive drug delivery, drug permeation-enhancing effect, and showed in situ gelling behavior owing to interand intramolecular disulfide bonds formation when it came in contact with physiological fluids. ${ }^{34-36}$ Trimethyl chitosancysteine (TMC-Cy) is a modified chitosan conjugate that combines the mucoadhesive and permeation improvement effects of TMC and thiolated derivatives. TMC-Cy insulin-loaded nanoparticles have been developed and have demonstrated high insulin encapsulation efficiency and mucoadhesion compared to TMC-insulin nanoparticles. ${ }^{37}$

Hydrophobic chitosans are chemically modified derivatives that have enhanced stability because of the decrease in the process of matrix hydration and, therefore, show high resistance to gastric enzymatic degradation. Chitosan chemically modified through introduction of carboxylic acid group renders chitosan poorly hydrophilic because of nonionization of the introduced carboxylic group in the acidic environment, while these derivatives are highly hydrophilic in the basic conditions. Chitosan succinate and chitosan phthalate are common examples that showed an insulin-loading capacity of approximately $60 \%$ and protected insulin from the gastric enzyme degradation. ${ }^{38,39}$ Lauryl succinyl chitosan possesses negatively charged mucoadhesive properties and was developed and utilized in the preparation of insulin-loaded micro- and nanoparticles. The prepared particles combined the hydrophilic and hydrophobic characters because of the presence of succinyl and lauryl moieties, respectively, and were found to augment chitosan mucoadhesiveness as well as insulin permeability and release when compared to chitosan particles. ${ }^{40}$ Another way to introduce a hydrophobic group to chitosan was achieved by acylation using sodium salts of medium-chain fatty acids, fatty acid chlorides, and lactones for use as a polymeric matrix in drug delivery. Lauric, caprylic, and capric acids are examples of fatty acids used to improve the permeability of the incorporated compounds, especially those of hydrophilic compounds such as insulin..$^{41,42}$ Oleoyl and octanoyl chitosan derivatives are examples of $\mathrm{N}$-acylated chitosans produced with fatty acylchlorides, in which the former showed higher resistance to gastric enzymatic degradation, enhanced mucoadhesiveness, and permeability. ${ }^{43}$ 
Synthesis of mono- $N$-carboxymethyl chitosan (MCC) is achieved by chemical modification of the chitosan amino groups with glyoxylic acid in presence of sodium borohydride as a reducing agent. ${ }^{44} \mathrm{MCC}$ is compatible with anionic agents and has been reported for its application in tissue culture as it decreases the transepithelial electrical resistance of Caco-2 cell monolayers. ${ }^{44}$

Chemical grafting of chitosan is a process by which one or more species of blocks are connected as a side chain to the main chitosan chain, resulting in the formation of macromolecular copolymers with modified physical and chemical properties. The characteristics of the newly formed copolymer depend on length, number, and molecular structure of the side chain(s). ${ }^{45}$ Chitosan might be grafted using radiation, free radical, or enzymatic and cationic copolymerization. Chitosan-poly(ethylene glycol) diacrylate and chitosan derivative with galactose groups have been produced using this technique by graft copolymerization of the macromonomer onto the chitosan backbone and chitosan amine group, respectively. ${ }^{46,47}$

\section{Chitosan micro-/nanoparticles as drug delivery system}

Among the novel drug delivery systems investigated, chitosan micro-/nanoparticles have offered great promise in oral, parenteral, topical, and nasal applications. ${ }^{48-50}$ In these systems, the drug is either confined and surrounded by a polymeric membrane or is uniformly dispersed in the polymer matrix. The size and surface characteristics of the prepared particles play an important role in their transport across the biological cell membranes. These particles could be used to deliver the pharmaceutically active agent in a controlled and, sometimes, site-specific manner. The mucoadhesive nature of chitosan renders the prepared particles the ability to improve both drug absorption and bioavailability because of extended drug contact with the mucosal layer and the high surface-tovolume ratio of nanoparticles that might also enhance this effect. Drug release at a specific site and for an extended period of time could also be achieved by mucoadhesion where chitosan adhere to specific mucosal surfaces in the body such as buccal, nasal, and vaginal cavities. ${ }^{51-53}$

Chitosan microparticles have shown varied applications in the delivery of a range of compounds owing to particle size reduction by micronization and their mucoadhesive properties. Dastan and Turan ${ }^{54}$ developed chitosan-DNA microparticles and reported a sustained-release profile of DNA from the prepared microparticles with a potential transfer of the DNA into Human embryonic kidney, Swiss 3T3, and HeLa cell lines. Another research group prepared chitosan-DNA microparticles that have demonstrated suitable in vitro characteristics for mucosal vaccination in simulated intestinal fluid and simulated gastric fluid. ${ }^{55}$ Their role in protein and peptide delivery has been illustrated by Chua et $\mathrm{al}^{56}$ after developing luteinizing hormone-releasing hormone chitosanbased microparticles as a vaccine delivery vehicle. Successful delivery of hormones by these particles extends their application for induction of immunity against some tumor antigens and microorganisms such as bacteria and viruses. ${ }^{56}$ Insulin delivery via the nasal route using chitosan microparticles was demonstrated by Varshosaz et $\mathrm{al}^{57}$ who showed that the insulin-loaded microspheres exhibited a $67 \%$ lowering in the blood glucose level compared to insulin administered by the intravenous route (with absolute insulin bioavailability of $44 \%$ ). Many research groups have thus described the applicability of chitosan microparticles in drug delivery. Encapsulation of diclofenac sodium, ${ }^{58} 5$-flurouracil,${ }^{59}$ cisplatin, ${ }^{60}$ felodipine, ${ }^{61}$ and hydroquinone ${ }^{62}$ into these carriers has been reported, and the designed microparticles generally exhibited a controlled-release effect. Chitosan magnetic microparticles (CMM) are a special class of chitosan microparticles that have been developed and find wide applications in the delivery of anticancer drugs or radionuclide atoms to a targeted tissue ${ }^{63}$ by binding the drug or the radioactive atom to a magnetic compound, which is then injected into the blood and stopped at the targeted tissue by an externally applied magnetic field. ${ }^{64}$

One drawback of drug-loaded polymeric microspheres is the undesirable drug burst effect that is usually observed, which limits their application as a drug delivery system. ${ }^{65-67}$ Coating of chitosan microspheres by another polymer such as alginate has been reported to enhance the drug encapsulation efficiency, increase the stability, and reduce the burst release of the incorporated therapeutic agent. As the hydrophilic character and solubility of chitosan is increased in acidic medium, the effect that leads to limit the ability of chitosan to control the release and affect stability of loaded drugs, coating the surface with acid-resistant polymer such as sodium alginate might overcome these drawbacks. Alginate, an anionic polysaccharide polymer, electrostatically interacts with the cationic chitosan and produces a polyelectrolyte complex that enhances chitosan characters. This effect was reported by Li et a ${ }^{68}$ for alginate-coated chitosan microspheres employed for vaccine delivery. Another research group illustrated the success of this approach in enhancing the encapsulation of lisinopril. ${ }^{69}$ Alginate-coated chitosan microspheres have also been reported as good 
vectors for oral administration of protein and peptides, such as insulin with enhanced insulin stability, sustained-release effect, and ability to reduce the blood glucose level in diabetic rats for more than 60 hours following oral administration. ${ }^{70}$ Another way to decrease the burst effect and enhance stability in pure chitosan microspheres was achieved by formation of polymer/layered silicate composites. ${ }^{71}$ Attapulgite, a nanosized silicate clay naturally occurring polymer used in drug delivery, ${ }^{72}$ has been introduced into cross-linked diclofenac sodium chitosan microspheres in which the prepared chitosan/attapulgite hybrid microspheres exhibited narrow size distribution and minimum drug release in the simulated gastric fluid. ${ }^{73}$

Drugs of limited aqueous solubility and patients suffering from instability in the GIT show poor absorption, low bioavailability, and bad therapeutic responses. ${ }^{74,75}$ Polymeric nanoparticles have been reported to conquer these problems. ${ }^{76,77}$ Development of chitosan nanoparticles has maximized the benefits of chitosan as a polymeric drug carrier by enhancing drug aqueous solubility, systemic absorption, bioavailability, and stability. Curcumin is a common example of these drugs, and the preparation of curcumin-loaded chitosan nanoparticles has been reported to enhance the drug solubility and stability in the GIT. ${ }^{78}$ Facilitation of the transmucosal delivery of two hydrophobic drugs, triclosan and furosemide, has been achieved by developing drug-loaded chitosan nanoparticles. ${ }^{79}$ Low-molecularweight heparin (LMWH) has been loaded into chitosan nanoparticles and showed improved oral absorption and relative bioavailability of $517 \%$ when compared to a solution of LMWH. ${ }^{80}$ Recently, chitosan nanotherapeutics have received great attention in the field of oncology because of enhanced tumor targeting, ability to load different hydrophobic anticancer drugs, and the ability to control the anticancer drugrelease rate. ${ }^{81,82}$ Chitosan-loaded paclitaxel nanoparticles illustrated excellent tumor-homing ability after systemic administration into SCC7 tumor-bearing mice. ${ }^{83}$ Moreover, an augmented systemic absorption of some peptides has been illustrated after formulation of these peptides as chitosan nanocarriers. ${ }^{84-86}$ Protein/siRNA-loaded chitosan nanoparticles have been prepared and have showed 98\% entrapment efficiency with adequate stability. ${ }^{87}$ Bovine serum albumin has been encapsulated into nanoparticles of chitosan, and the prepared particles showed acceptable physicochemical properties as indicated by the size range $(200-580 \mathrm{~nm})$ and high positive zeta potential. ${ }^{88}$ Genetic immunization using chitosan nanoparticles-loaded plasmid DNA was investigated, and results showed measurable and quantifiable levels of gene expression and considerable antigen titer. ${ }^{89}$ Other workers investigated the potential of these nanoparticles as carriers for antigens by using recombinant hepatitis B surface antigen, in which the nanoparticles were stable, able to associate efficiently with the antigen $(>60 \%)$, kept the antigenic epitope intact, released the antigen in a controlledrelease manner, and illustrated induction of immunization through substantial anti-HBsAg IgG levels. ${ }^{90}$ Chitosan nanoparticles for oral delivery of insulin have been successfully formulated, and these demonstrated improved interaction with the intestinal epithelium, enhanced in vitro as well as in vivo absorption, and acceptable insulin bioavailability. ${ }^{86-91}$ As previously illustrated during the discussion of chitosan microparticles, magnetic nanosized chitosan particles were also developed as a special type of chitosan nanoparticles and showed sustained drug release with minimal toxicity. This behavior was noticed after preparation of camptothecin magnetic chitosan nanoparticles in which polyethylene glycol was coupled onto the prepared magnetic nanoparticles to increase their biocompatibility. ${ }^{92}$

As has been mentioned during the discussion of microparticles, the initial drug burst-release effect was still a problem with these systems. It has been reported that this weakness still presents some difficulties with the chitosan nanoparticulate system. ${ }^{88}$ Coating of the nanoparticles can diminish this problem. Poly-lactic-co-glycolic acid was used as a polymeric coating material for dexamethasone chitosan nanoparticles in cultured cells, with a considerable modulation in drug release as well as controlled drug delivery. ${ }^{93}$ Alginate has been also used as a coating material for chitosan nanoparticles. Alginate-coated chitosan nanoparticles loaded with low-molecular-weight heparin, enoxaprin, were synthesized and exhibited modified drug-release profile with overall significant increase in oral bioavailability when compared to drug solution and approximately a $60 \%$ decrease in thrombus formation in experimental rat venous thrombosis model. ${ }^{94}$

\section{Methods of preparation}

Top-down and bottom-up are the two techniques used to develop micro- and nanoparticle drug carriers. In the latter, the particulate system is prepared from a state of molecular dispersion type and is allowed to associate with subsequent formation of solid particles. Bottom-up techniques, therefore, seek to arrange smaller components into assemblies of complex structure, While the former starts with large size materials and breaks these down into smaller particles. Conventional nanoparticle synthesis usually depends on bottom-up techniques. ${ }^{95}$ 
Different methods have been utilized in the preparation of chitosan micro- and nanoparticles. The particle size, stability of the active constituent and the final product, residual toxicity present in the final product, and the kinetic of the drug-release profile are factors that should be considered during selection of the method. ${ }^{13}$ During the preparation of chitosan particulate systems, the size of the prepared particles is greatly dependent on chitosan molecular weight, chitosan chemical structure, particularly the degree of deacetylation, and on the method of preparation. As a general rule, higher molecular weight chitosan produces larger-size particles. ${ }^{96}$ Different methods are available to prepare chitosan micro-/ nanoparticles in which the drug is mostly bound to chitosan by hydrogen bonding, electrostatic interaction, or hydrophobic linkage. Generally, loading the therapeutic agent into chitosan micro-/nanoparticles may be achieved either during the preparation process or after the particles have been formed. In the former, the therapeutic agent is incorporated and embedded in the chitosan matrix, whereas in the latter the therapeutic agent is adsorbed on the particle surface. Usually, the aim is to achieve high entrapment efficiency, which could be accomplished by incorporation into the matrix, but the therapeutic agent could be affected by the preparation method, additives, etc. ${ }^{13}$ Generally, selection of the method is greatly dependent on the nature of therapeutic agent and the type of device utilized in the delivery. ${ }^{13}$ A list of methods used in the preparation of these particles is given in Table 1. All these methods involve the bottom-up production process, in which assembly of the dissolved molecules is achieved to form a definite micro- or nanoparticulate structure. ${ }^{97}$

The techniques used in the preparation of chitosan micro-/ nanoparticles loaded with thermosensitive or less stable substances such as proteins, peptides, hormones, vaccines, plasmid DNA, and antigens may be broadly classified into cross-linking techniques and drying techniques. Crosslinking could be achieved chemically or physically. The stability of these thermosensitive or less stable substances are strongly affected by the organic solvent and the crosslinking agent used, with the consequence of denaturation or chemical modification. ${ }^{98}$ So, physical cross-linking and drying techniques, such as spray drying, are preferred and widely used for these substances. Recently, reverse micellar method has been introduced. These aforementioned techniques - cross-linking, drying, and reverse micellar - in addition to sieving and solvent evaporation were used in the preparation of other drugs of different pharmacotherapeutic groups. An insight on these methods is described in the following sections.

Table I Methods of preparation of chitosan micro/nanoparticles loaded with different pharmacotherapeutic agents

\begin{tabular}{|c|c|c|}
\hline Encapsulated agent & Method of preparation & Examples \\
\hline Thermosensitive and less & - Cross-linking techniques & \\
\hline \multirow[t]{9}{*}{ stable substances } & I. Physical cross-linking & \\
\hline & I.I. lonic gelation & $\begin{array}{l}\text { Interleukin-2, insulin, tetanus toxoid, DNA, albumin, and influenza } \\
\text { subunit antigen }\end{array}$ \\
\hline & I.2. Complex coacervation & Plasmid DNA \\
\hline & I.3. Polyelectrolyte complex (PEC) & Insulin, VEGF, heparin, and hyaluronan \\
\hline & 2. Chemical cross-linking & Insulin, BSA, and progesterone \\
\hline & - Drying technique & \\
\hline & I. Spray drying & Salmon calcitonin and BSA \\
\hline & 2. Super critical drying & Insulin \\
\hline & - Reverse micellar method & BSA \\
\hline \multirow[t]{9}{*}{$\begin{array}{l}\text { Other drugs of different } \\
\text { pharmacotherapeutic groups }\end{array}$} & - Emulsion cross-linking & $\begin{array}{l}\text { Diclofenac sodium, aspirin, cisplatin, 5-fluorouracil, mitoxantrone, } \\
\text { griseofulvin, phenobarbitone, pentazocine, theophylline, } \\
\text { pamidronate, lisinopril, rabeprazole, and suberoylbisphosphonate }\end{array}$ \\
\hline & - Emulsion droplet coalescence & Gadopentetic acid \\
\hline & - Sieving method & Clozapine \\
\hline & - Reverse micellar method & Doxorubicin \\
\hline & - lonic gelation & Felodipine, triclosan, and furosemide \\
\hline & - Precipitation/coacervation & Prednisolone, ketorolac, and doxorubicin \\
\hline & - Spray drying & $\begin{array}{l}\text { Betamethasone, ampicillin, oxytetracycline, cetylpyridinium } \\
\text { chloride, cimetidine, famotidine, nizatidine, vitamin D, diclofenac } \\
\text { sodium, ketoprofen, and metoclopramide- } \mathrm{HCl}\end{array}$ \\
\hline & - Thermal cross-linking & Indomethacin \\
\hline & - Solvent evaporation & Metformin \\
\hline
\end{tabular}

Abbreviations: BSA, bovine serum albumin; VEGF, vascular endothelial growth factor. 


\section{Cross-linking techniques}

Physical cross-linking

The ionic cross-linking method is the most common among physical cross-linking techniques since the preparation procedure is simple, does not involve use of organic solvent or high temperature, and no chemical interaction is involved. ${ }^{33,99}$ These advantages make this method efficient and safe for production of thermosensitive therapeutic agents such as proteins, peptides, hormones, and vaccines loaded into chitosan particulate systems. Assembly and formation of the particles is achieved by ionic cross-linking between chitosan or one of its derivatives, being cationic in nature, and either negatively charged macromolecules or anionic cross-linking agents. Acidic solution of chitosan is prepared, and the ionic cross-linker is added dropwise along with stirring and sonication. If cross-linking is achieved by anionic cross-linkers such as sodium sulfate or tripolyphosphate (TPP), the process is called ionic gelation, whereas negatively charged polyelectrolyte macromolecules, such as cyclodextrin derivatives, dextran sulfate, and poly- $\gamma$-glutamic acid produce electrostatic polyelectrolyte complexes (PEC) of ionic cross-linking type.

Formulation of felodipine-loaded chitosan microparticles has been achieved by ionic gelation. The chitosan molecular weight and concentration, concentration of the cross-linking agent (TPP), and TPP $\mathrm{pH}$ have been reported to play an important role in the drug-release pattern. ${ }^{100}$ Slower felodipine release was obtained from TPP solution of low $\mathrm{pH}$ and higher TPP concentration, and higher chitosan molecular weight and concentration. Triclosan and furosemide, two hydrophobic drugs, were loaded into chitosan nanoparticles by ionic crosslinking of chitosan with TPP, and the release profile of both drugs from the prepared nanoparticles was characterized by fast initial release followed by a controlled-release stage. ${ }^{79}$ TPP is widely used to prepare chitosan nanoparticles that have been successfully employed as a carrier for proteins and antigens such as insulin, ${ }^{91}$ tetanus toxoid, ${ }^{101}$ albumin, ${ }^{102}$ and influenza subunit antigen. ${ }^{103}$ Chitosan-loaded interleukin-2 (IL-2) microparticles were prepared using sodium sulfate as the anionic cross-linker. ${ }^{104}$

Complex coacervation is a process of liquid-liquid phase separation that occurs when two solutions containing oppositely charged ions are mixed, resulting in the formation of an ionic complex. ${ }^{105}$ Plasmid DNA was successfully loaded into chitosan nanoparticles of size range $450-820 \mathrm{~nm}$ by this method, and the encapsulation was more than $90 \%$ for chitosan of high degree of deacetylation and the release was extended for 24 hours. ${ }^{106}$ As chitosan is a cationic polymer that is soluble in acidic solution, it is also possible to precipitate chitosan from its aqueous solution by addition of alkali, which is the theoretical principle of the precipitation/ coacervation method. The technique involves preparation of chitosan aqueous solution that is introduced through a nozzle into aqueous or hydroalcoholic solution of sodium hydroxide or ethanediamine by blowing or dropping. The precipitated chitosan microparticles are separated by filtration/centrifugation and finally washed with hot and cold water. A cross-linking agent may be added to increase the hardness of the obtained particles, which can extend the drug release. Prednisolone-loaded chitosan microspheres were prepared by the precipitation method and were able to enhance the transport of prednisolone across the epithelial barrier. ${ }^{107}$ Complex coacervation, as already described, has been employed for the preparation of ketorolac tromethamine chitosan microspheres that controlled the drug release, while potentially improving patient compliance due to the decrease in dosing frequency. ${ }^{108}$

PEC chitosan nanoparticles produced through ionic interaction with the negatively charged dextran sulfate and loaded with insulin ${ }^{109}$ or vascular endothelial growth factor $(\mathrm{VEGF})^{110}$ was reported. In another study, poly- $\gamma$-glutamic acid has been used in the preparation of PEC chitosan nanoparticles, which reduced the transepithelial electrical resistance of Caco-2 cell monolayers. ${ }^{111}$ Recently, selfassembled, electrostatic PEC chitosan particles have been developed for delivery of some proteins such as insulin, heparin, hyaluronan, and VEGF. ${ }^{109,12-116}$ Self-assembly is achieved through electrostatic interaction between the cationic amino group of chitosan and the chemically modified $N$-anionic chitosan amines such as $N$-sulfated chitosan. Schatz et al ${ }^{116}$ reported formulation of selfassembled chitosan nanoparticles by electrostatic interaction between the protonated amino residues of chitosan, being cationic, and the sulfate functions, being anionic, and the nanoparticles were stabilized by an excess of surface sulfate groups.

Thermal cross-linking is another way of physical crosslinking in which citric acid, a commonly used cross-linking agent in this method, is added to an aqueous chitosan acidic solution in a constant molar ratio between citric acid and chitosan. The mixture is cooled to $0^{\circ} \mathrm{C}$ and added while stirring to an oily phase, such as corn oil or sesame oil, previously cooled to $0^{\circ} \mathrm{C}$. The emulsion is thermally crosslinked at $120^{\circ} \mathrm{C}$, and the obtained microspheres are filtered, washed, and finally dried. Indomethacin-loaded chitosan microspheres were prepared by this method. ${ }^{117}$ 


\section{Chemical cross-linking}

In this method, chitosan micro-/nanoparticles are formed through a chemical interaction between a cross-linking agent and the primary amino groups of chitosan. Common cross-linkers are glutaraldehyde, $p$-phthaldehyde, ascorbyl palmitate, and dehydroascorbyl palmitate. Chitosan microparticles prepared using ascorbyl and dehydroascorbyl palmitate have lower toxicity and high insulin-loading efficiency, and release insulin in a controlled-release manner, for approximately 80 hours, when compared to that produced using di-aldehydes, glutaraldehyde, and $p$-phthaldehyde as chemical cross-linkers. ${ }^{118}$ Chemical cross-linking may take place either through one or two steps. The procedure involves formation of a water/oil (w/o) emulsion in which chitosan and the therapeutic agent are in the aqueous phase that is emulsified into external immiscible solvent. The cross-linking agent is gradually added and, finally, the prepared particles are separated and washed with appropriate solvent to yield the desired particle. ${ }^{119}$ Ascorbyl palmitate and dehydroascorbyl palmitate were used as a chemical cross-linking agent during the preparation of chitosan-loaded insulin microparticles in an external mineral oil phase. ${ }^{118}$ Formation of these particles in the internal aqueous phase of w/o emulsion improves the entrapment of the therapeutic agent as the external oil phase prevents the escaping of the therapeutic agent. ${ }^{120}$ An illustration of the steps involved in the production of chitosan particles by this technique is shown in Figure 2.

Some additives may be added to enhance stability and encapsulation efficiency of the therapeutic agent or decrease its leakage. Gelatin has been added to the aqueous phase to enhance insulin stability and encapsulation. ${ }^{121}$ Preparation of chitosan microparticles containing bovine serum albumin (BSA) has been reported by this method. ${ }^{122}$
Drugs of different pharmacotherapeutic groups such as nonsteroidal anti-inflammatory, antineoplastic, antifungal, antiseizure, opioid, methyl xanthenes, angiotensin-converting enzyme inhibitor, and bone-related drugs have been loaded into chitosan microparticles. ${ }^{13}$ Glutraldehyde, glutraldehyde extracted in toluene, and ascorbyl palmitate are commonly used cross-linkers, while liquid paraffin or a mixture of mineral oil/petroleum ether is used as external oil phase. Common examples of drugs in each pharmacotherapeutic group are listed in Table 1. Recently, Ahmed and El-Say ${ }^{120}$ have developed rabeprazole chitosan nanoparticles within a w/o nanoemulsion by emulsifying the aqueous phase into paraffin oil containing a surfactant mixture of spans and tweens. The optimized nanoparticles showed a nanosize range, $120 \pm 32 \mathrm{~nm}$, and were spherical in shape as indicated by the scanning electron micrograph (Figure 3 ).

Recently, emulsion droplet coalescence technique that uses the principles of emulsion cross-linking and precipitation has been developed. Two separate emulsions are prepared using two different aqueous phases in paraffin oil. The aqueous phase of the first emulsion consists of chitosan and the studied anionic drug, while that of the second emulsion is composed of chitosan in sodium hydroxide solution. The two emulsions are mixed under high-speed stirring, which allows droplets of each emulsion to coalesce randomly, and the newly formed droplets are precipitated. ${ }^{123}$ The advantage of this method over the emulsion cross-linking method lies in that it allows an electrostatic interaction between the free amino groups of chitosan and the used anionic drug that permits higher drug loading. This mechanism was not possible in the emulsion cross-linking technique owing to the blocking of the chitosan amino groups by the cross-linker. Gadopentetic acid, a bivalent anionic drug, was loaded into a chitosan nanoparticle by this method. ${ }^{123}$

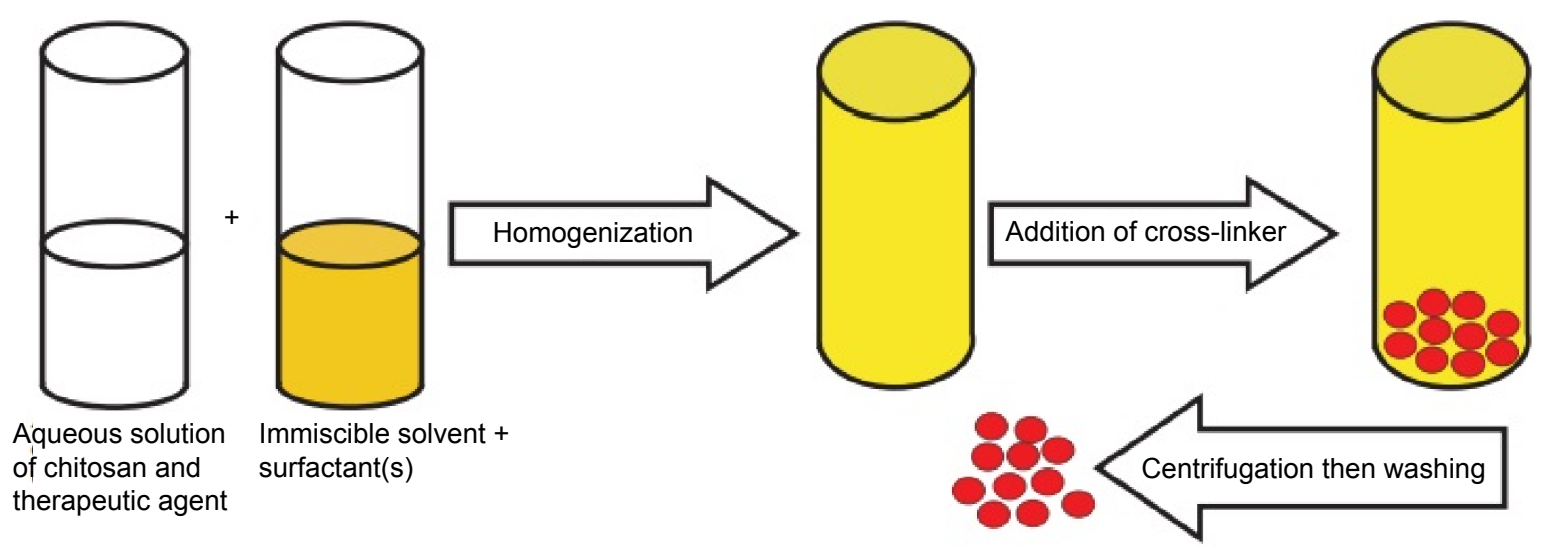

Figure 2 Schematic representation of production of chitosan micro/nanoparticles by chemical cross-linking. 


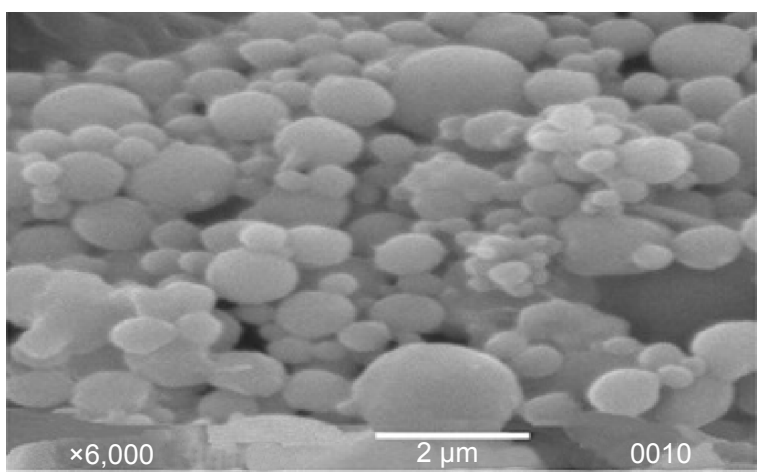

Figure 3 Scanning electron micrograph of chitosan nanoparticles produced using nanoemulsion internal cross-linking technique.

\section{Drying techniques}

Drying is the process of water/solvent removal from liquids, solids, or semisolids by evaporation, where the vapor that is produced is removed by vacuum. Hot air, microwave, spray drying, freeze drying, supercritical drying, and natural air drying represent the general methods of drying. Spray drying and supercritical drying are the most commonly used in the preparation of chitosan particulate systems as they are simple, adapt well with the incorporated drug, are easily scaled up, and have the ability to produce particles of different size and high stability.

\section{Spray drying}

Spray drying has been reported for manufacturing of granules and dry powders from drug-excipient mixtures either in a solution or suspension. ${ }^{124}$ The expediency of this method extended to include preparation of microparticles from different polymeric materials loaded with protein, ${ }^{125}$ vaccine antigens, ${ }^{126}$ and drugs. ${ }^{127}$ Spray drying offers an easy, efficient, one-step, and protein-friendly method for protein-loaded chitosan micro-/nanoparticles. The basic principle of spray drying relies on using a stream of hot air to dry atomized droplets. As illustrated in Figure 4, the process involves preparation of aqueous chitosan-protein solution that is sprayed through a nozzle into a drying chamber to get the desired particles. BSA and salmon calcitonin are examples of proteins loaded into chitosan microparticles by this method. ${ }^{128,129}$ Drugs from different pharmacotherapeutic groups have been loaded into chitosan microparticles and studied for their effect as potential drug carrier. Chitosan has been used as a micro-/nanocarrier for corticosteroid, antimicrobial, proton pump inhibitor, NSAID, and antiemetic drugs that have been formulated by this method. ${ }^{13}$ Examples of drugs loaded into chitosan particles by this method are listed in Table 1. The prepared particles were spherical, of smooth surface and narrow size distribution and showed good drug stability and high drug-entrapment efficiency. Other advantages of this method are the possibility of surface cross-linking and coating the spheres during the manufacturing steps, which could enhance stability and control drug release. He et al ${ }^{130}$ reported on the preparation of nizatidine, cimetidine, and famotidine cross-linked and un-cross-linked chitosan microspheres using the spray drying technique, and ethyl cellulose-coated chitosan microspheresloaded ergocalciferol were successfully produced by the same method. ${ }^{131}$ The size of the prepared particles is influenced by spray flow rate, extent of cross-linking, and inlet air flow rate. Large particles were produced using high spray flow rate from large-sized nozzles and when there was a decrease in the extent of cross-linking, while smaller particle size was obtained at greater airflow rates and not by the inlet air temperature being between $140^{\circ} \mathrm{C}$ and $180^{\circ} \mathrm{C}$. Most recently, vildagliptin nanospheres, of smooth surface, were prepared using the spray-drying technique. The prepared nanospheres were characterized by high drug content and nanospheres percentage yield of $76.2 \% \pm 4.6 \%$ and $83 \% \pm 2 \%$, respectively. ${ }^{132}$

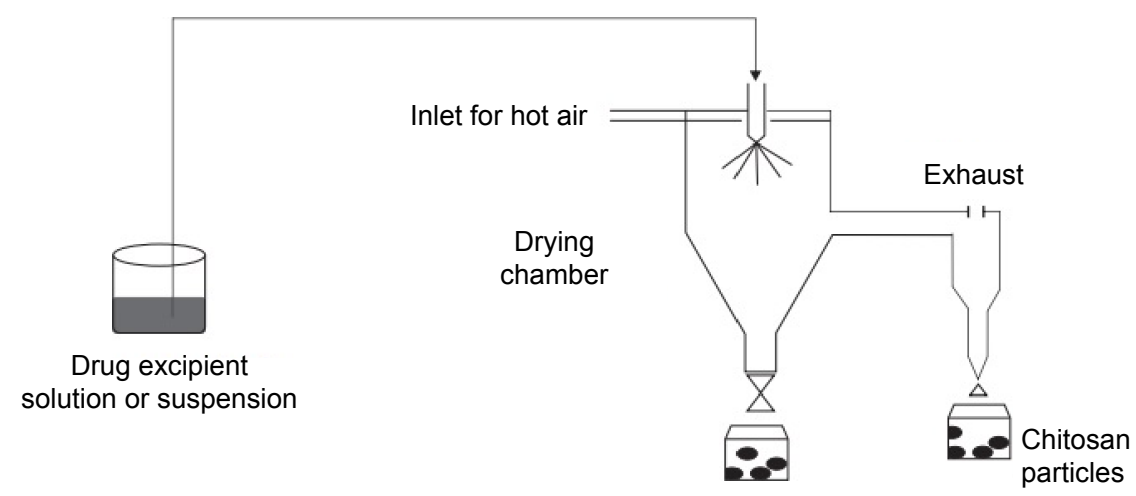

Figure 4 Schematic representation of the spray-drying technique used for the manufacturing of chitosan particulate systems. 


\section{Supercritical drying}

This is a process of drying the liquid in a substance by converting it into a gas without crossing the phase boundary between the liquid and gas and without affecting the substance nanostructure network. A critical point, of specific temperature and pressure, is a characteristic feature of pure substance at which gaseous and liquid states of the substance has liquidlike viscosity and density, and so are difficult to differentiate. Substances possessing this property easily penetrate into substances like a gas and dissolve materials like a liquid. ${ }^{133}$ Some fluids such as carbon dioxide, Freon, and nitrous oxide are suitable for drying by this process, and they can easily penetrate into the material like gas and dissolve the substance similarly as liquid. ${ }^{133}$ Chitosan microparticles loaded with insulin have been successfully prepared using supercritical fluid drying method suitable for inhalation. ${ }^{134}$ This method is fast, economical, and could produce much smaller particles suitable for delivery by the inhalational route. ${ }^{135,136}$

\section{Reverse micellar method}

Reverse micelles are water droplets in the nanometer size (1-10 nm) dispersed in organic solvent because of the effect of surfactants. ${ }^{137}$ The aqueous core of these nanosized droplets can be used as a reactor to prepare nanoparticles. The preparation method includes preparation of aqueous drug-chitosan solution that is to be added under stirring to a mixture of organic solvent and surfactant molecules. A cross-linking agent is added, and the mixture is left on the stirrer overnight for complete cross-linking. The organic solvent is then evaporated to get a dried mass. To remove the surfactant, the obtained dried mass is dispersed in water and a suitable salt is added to precipitate the surfactant out, and finally the drug-loaded chitosan nanoparticles are recovered by centrifugation. Figure 5 represents the steps involved in this method. The reverse micellar method has been used to prepare BSA-loaded chitosan nanoparticles in a size range of 80-180 nm. ${ }^{138}$ The doxorubicin dextran complex was loaded into chitosan nanoparticles using $n$-hexane as organic solvent, sodium bis(ethyl hexyl) sulfosuccinate as surfactant, and glutraldehyde as cross-linker. The prepared nanoparticles were of $100 \pm 10 \mathrm{~nm}$ size and enhanced the permeability and retention effect of doxorubicin, which was reflected in improving the drug therapeutic effect and reduction of the side effect in solid tumor. ${ }^{139}$

\section{Sieving method}

Preparation of chitosan microparticles by this method involves formation of $4 \%$ chitosan hydrogel containing the drug, after which a cross-linking agent such as glutraldehyde is added to produce a cross-linked chitosan hydrogel that is passed through a sieve of definite size to get the drug-loaded microparticles. The excess glutraldehyde is removed by washing the obtained microparticles with $0.1 \mathrm{~N}$ sodium hydroxide, and then the particles are dried in an oven at $40^{\circ} \mathrm{C} .{ }^{140}$ Clozapine microparticles of the size range 543-698 $\mu \mathrm{m}$ showed an extended drug release up to 12 hours when prepared by this method.

\section{Solvent evaporation}

In this method, a polymeric drug solution in a volatile solvent such as acetone is prepared and emulsified into a nonaqueous phase such as liquid paraffin. The mixture is kept under stirring until complete evaporation of the solvent, and the formed microspheres are filtered, washed with suitable solvent such as petroleum ether, and finally dried. Drying is usually achieved by air or under vacuum. Metformin-loaded chitosan microspheres were successfully obtained using this procedure. ${ }^{141}$

In general, the entrapment efficiency and particle size of the prepared particulate systems are affected by various processing and formulation parameters such as chitosan concentration, chitosan molecular weight, type of the chitosan derivative, nature of the drug, initial drug concentration used, drug-polymer ratio, nature of the cross-linking agent,

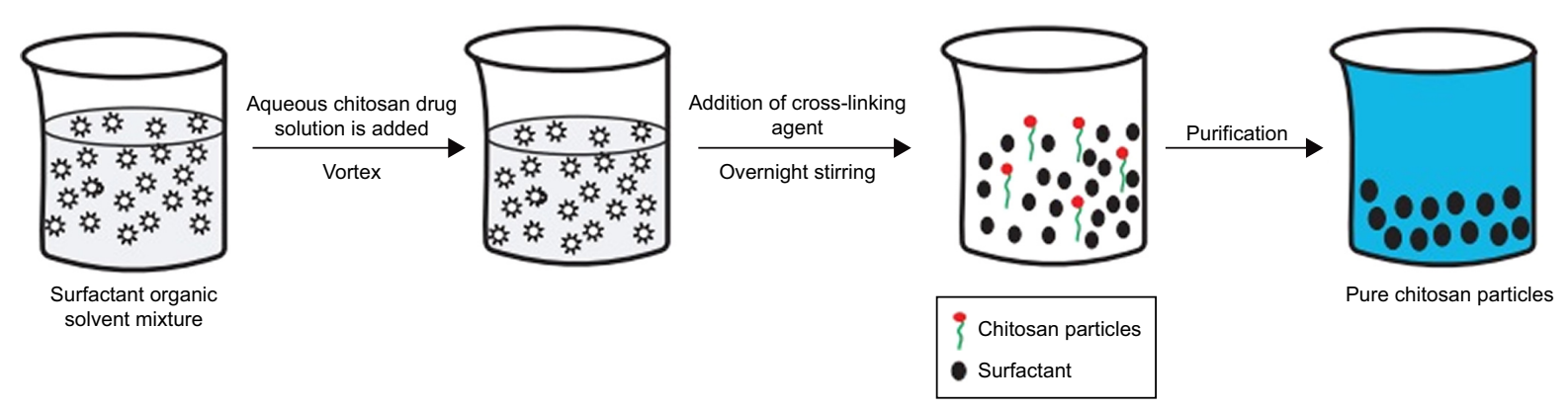

Figure 5 Schematic representation of reverse micellar technique. 
type and concentration of the surfactant, and stirring speed. Optimizing these parameters using suitable optimization software is helpful in achieving the desired particles.

\section{Characterization of chitosan micro-/ nanoparticles}

After preparation of the chitosan particulate system, parameters such as particle size analysis, zeta potential, morphological and surface characteristics, drug content, encapsulation and loading efficiency, specific surface properties, in vitro release, and characterization of the targeting action are analyzed.

Perhaps the most important physical property of particulate systems is particle size. Measurement of this property is critical to the success of technique employed during manufacturing. Malvern has developed instruments for all types of particle size analysis and characterization of particles ranging from the subnanometer to millimeter range. Table 2 lists the technology and particle size instruments suitable for each measuring particle size. Information about the technology employed in each instrument could be found in the website for Malvern. ${ }^{142}$ In addition to the technologies listed in Table 2, photon correlation spectroscopy is a technique widely used to characterize the nanoparticles' particle size.

Morphology, particle size distribution, and mean particle diameter characterization of the prepared microparticles could be carried out using optical microscope of suitable magnification power. A randomly chosen dried microparticles sample is examined under the eyepiece of the microscope that was calibrated so that the unit in the eyepiece micrometer is equal to a definite size in $\mu \mathrm{m}$. The individual particle size is calculated, from which the size distribution and mean particle diameter are determined. For microparticles of size greater than $90 \mu \mathrm{m}$, the micromeritic properties are studied by determining the particle size distribution, geometric mean diameter, and geometric standard deviation. ${ }^{143}$ The particle size distribution is determined using the sieve analysis. To do so, a definite weight of microparticles is placed on top of a standard set of sieves having a determined size range (eg, 710-90 $\mu \mathrm{m}$ ) and is shaken for a specified time, usually 10 minutes, using an electric shaker. After the shaking period, the weight of the microparticles retained on each sieve is collected and weighed. The mean particle size is calculated using the following equation:

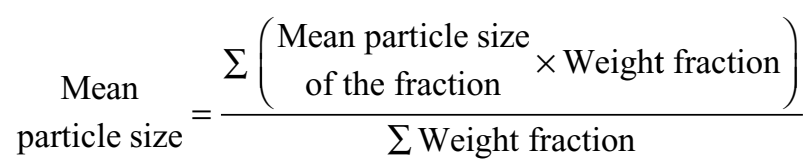

The geometric mean diameter and geometric standard deviation are estimated from the probability scale plot obtained by plotting the logarithm of the particle size against the cumulative percent frequency.

When microparticles are of very low range, 5-10 $\mu \mathrm{m}$, sieving is not an accurate way to analyze particle size distribution. Techniques such as Feret, Martin, Krumbein, or Heywood diameter are very helpful in this case. Feret's diameter, the most common among these, analyzes the particle size and size distribution through measuring the distance between two parallel tangential lines on the particle along a specified direction. ${ }^{144}$

For nanoparticulate system, the morphological and surface characteristic of the prepared particles are usually evaluated using a scanning electron microscope (SEM), which provides image of the sample and information about the sample's surface through scanning it with a focused beam of electrons that interact with the sample atoms and produce various signals that are detected using a highly sensitive detector. Unlike the optical microscope and telescope, the detector is not a camera and so has no diffraction limit for resolution. Samples of the dried particles are mounted in a metal stub and coated with a thin film of gold, or other conducing material, under vacuum, before the sample is observed by SEM, as observed in Figure 3. SEM

Table 2 The technology, instrument, and particle size range suitable for each particle size

\begin{tabular}{lll}
\hline Technology & Particle size range & Instrument \\
\hline Taylor dispersion analysis & $0.2 \mathrm{~nm}$ to $>20 \mathrm{~nm}$ & Viscosizer \\
Dynamic light scattering & $<1 \mathrm{~nm}$ to $>1 \mu \mathrm{m}$ & Zetasizer \\
Nanoparticle tracking analysis & $<30 \mathrm{~nm}$ to $>1 \mu \mathrm{m}$ & NanoSight \\
Resonant mass measurement & $50 \mathrm{~nm}$ to $5 \mu \mathrm{m}$ & Archimedes \\
Laser diffraction & $<100 \mathrm{~nm}$ to $>2 \mathrm{~mm}$ & Mastersizer, Insitec, Spraytech \\
Spatial filter velocimetry & $<50 \mu \mathrm{m}$ to $6 \mathrm{~mm}$ & Parsum \\
Automated imaging & $<1 \mu \mathrm{m}$ to $>3 \mathrm{~mm}$ & Morphologi (G3 and G3-ID), Sysmex FPIA
\end{tabular}


also provides information about the surface smoothness, roughness, or porous structure, all parameters that might be helpful on the interpretation of subsequent analyses, such as the dissolution behavior or in vivo responses. ${ }^{145}$ SEM has been used to study the shape and occurrence of chitosan aggregates ${ }^{146}$ and also for studying alginate/chitosan nanoparticles. ${ }^{147}$ Transmission electron microscope (TEM) was also used to examine the shape of doxorubicin-loaded chitosan nanoparticles in which a drop of the prepared nanoparticles was deposited onto a formvar-coated copper grid and was vacuum dried before TEM specification. ${ }^{148}$

Zeta potential, which reflects the surface electric charges of the particles, are determined using zeta potential measurement, ZetaMeter (Staunton, VA, USA), which applies the principle of electrophoresis. An electric field is applied across the dispersed particles in which the particles will migrate to the oppositely charged electrode with a velocity that is proportional to the value of the zeta potential. The velocity of migration is measured using the technique of Laser Doppler Anemometer. The magnitude of zeta potential reflects the degree of electrostatic repulsion between charged particles. For dispersion system, high degree of zeta potential, negative or positive, indicates resistance of the particles to aggregation, and this denotes an apparently stable system. Rodrigues et $\mathrm{al}^{149}$ reported the use of laser Doppler anemometry in the measurement of zeta potential for chitosan/carrageenan nanoparticles.

Drug content, encapsulation efficiency, loading efficiency, and micro-/nanoparticles yield are other characteristics that should be calculated for the prepared micro-/nanoparticles before therapeutic administration. First, the drug content has to be determined using a suitable drug analytical method such as spectrophotometry or high-performance liquid chromatography (HPLC). Then, drug encapsulation efficiency and loading efficiency are determined by the following equations:

$\begin{gathered}\text { Encapsulation } \\ \text { efficiency }(\%)\end{gathered}=\frac{\begin{array}{c}\text { Amount of drug in a definite } \\ \text { mass of the prepared particled }(\mathrm{mg})\end{array}}{\begin{array}{c}\text { Theoritical amount of } \\ \text { drug in the same mass }(\mathrm{mg})\end{array}} \times 100$

Amount of drug in a definite

Loading $=\frac{\text { mass of the prepared particled }(\mathrm{mg})}{\text { Total mass of the particles }(\mathrm{mg})} \times 100$

Micro-/nanoparticles yield, however, is calculated from the following equation;
Yield $(\%)=\frac{\text { Total weight of the prepared particles }(\mathrm{mg})}{\text { Total weight of drug and polymers used }(\mathrm{mg})} \times 100$

For microparticles, the drug content is determined after crushing of the microparticles and extracting the drug in suitable solvent or after complete drug release from the microparticles that was suspended in water or buffer and left shaking for 24 or 48 hours. For nanoparticles, usually, the obtained dispersion of the nanoparticulate system is centrifuged at high speed, up to $100,000 \mathrm{rpm}$ according to the nanoparticle size, and the amount of the drug in the supernatant is analyzed, after which the drug content is determined indirectly.

The specific surface properties of the prepared particulate system could be examined using X-ray photoelectron spectroscopy (XPS) and time-of-flight secondary ion mass spectrometry (ToF-SIMS). Both provide information about the elements from which the particles originate, chemical bonding, and detailed molecular information with high sensitivity. The former identifies the size-dependent distributions and the chemical states of the elements, while the latter provides detailed surface and near-surface composition analysis, and so characterization and composition of the surface chemistry of the particles are illustrated. Casettari et al $^{150}$ studied the surface properties of PLGA/ chitosan microparticles using XPS and ToF-SIMS to identify the presence of chitosan on the prepared particles surface. Another research group used XPS and ToF-SIMS to study the surface analysis and matrix chemical composition of chitosan/carrageenan nanoparticle. ${ }^{149}$

Deformability of the prepared nanoparticles is measured by a simple filtration test method. A suspension of nanoparticles labeled with a fluorescent dye is prepared in phosphate buffer and passed through syringe filter membranes of decreasing pore sizes $(0.8-0.2 \mu \mathrm{m})$. The filtrate is observed for the presence of the dye using near-infrared fluorescent (NIRF) images, and the stability of the particles is confirmed by measuring the change in the molecular weight of the sample after incubation in PBS with or without $10 \%$ weight of serum at $37^{\circ} \mathrm{C}$ for 6 hours..$^{151}$

In vitro release test is used to determine the drug release profile from the prepared chitosan micro-/nanoparticles. The mechanism of drug release from these particles is related to 1) drug present on the particle surface, 2) drug diffusion from chitosan matrix, and 3) chitosan degradation and erosion. ${ }^{13}$ Generally, the drug release is diffusion controlled and follows the Higushi model, depending on the chitosan molecular weight, 
particle size and density, degree of cross-linking, excipients, polarity, $\mathrm{pH}$, and the presence of enzymes in the dissolution media. ${ }^{13,19}$ The diffusion mechanism of drug release involves penetration of water into the polymeric particulate system, which results in swelling of the matrix, then formation of rubbery polymeric matrix, and, finally, diffusion of the drug from the produced swollen rubbery polymeric matrix..$^{13}$ Deviation of the drug release from diffusion to zero order could be achieved from large-sized particles, usually in the microsize range, prepared using higher chitosan concentration at specific $\mathrm{pH}$ medium. Indomethacin chitosan microspheres exhibited this behavior at $\mathrm{pH}$ 7.4. ${ }^{117}$

Recently, characterization of the targeting action of drugloaded chitosan nanoparticles particularly to the cancer cell has been reported. Kim et al ${ }^{151}$ developed a paclitaxel-loaded chitosan nanoparticles containing Cy5.5, a near-infrared fluorescent (NIRF) dye, and evaluated their cytotoxicity on a culture of murine squamous carcinoma cells, as well as their targeting ability by performing in vivo and ex vivo NIRF imaging using a CCD camera image station in which the NIRF emission data of the tumor and major organs were recorded.

\section{Potential applications of chitosan micro-/ nanoparticles}

Drugs of different classes such as anticancer, anti-inflammatory, cardiovascular, antibiotics, antihistaminic, antithrombic, steroids, antiosteoporotic, antidiabetics, CNS acting, opioid analgesics, corticosteroids, antihyperlipidemic, antiemetics, proton pump inhibitors, enzymes, toxoids, DNA, hormones, growth factors, proteins, and amino acids have been loaded or encapsulated into chitosan particulate systems. ${ }^{22}$ Apart from the mentioned classes of drugs, chitosan/chitosan derivative nanoparticles have been used as a potential carrier for vaccines and as a nonviral vector for gene delivery. Both local and systemic immune responses have been produced following administration of vaccine-loaded chitosan nanoparticles. Immune response could be achieved by induction of antibodies; ${ }^{152}$ production of inflammatory mediators such as cytokines, interleukins, colony-stimulating factors, and granulocyte-macrophage colony-stimulating factor; ${ }^{153}$ enhancement of the capability of the antigen presentation to dendritic cells and stimulation of greater allogeneic T-cell proliferation, ${ }^{154}$ and increasing the retention of the administered vaccine at the injection site, which results in the induction of transient cellular expansion in the draining lymph nodes. ${ }^{155}$ Influenza vaccine, Cholera toxins, hepatitis B surface protein, Streptococcus equi bacterial extract containing antigen protein, and $\beta$-galactosidase are examples of vaccine antigens that have been loaded into these nanoparticles. ${ }^{155-159}$ The important feature in chitosan, particularly when formulated in particulate form and administered through parenteral or mucosal routes, is that it can be taken up and then processed by antigen-presenting cell, the effect that initiates an immune response against the loaded antigen. ${ }^{160}$ The role of these particles in gene delivery has sparked the use of these as a nonviral gene delivery vector. Delivery of genes by viruses suffers from low transfection, low amount of the gene introduced into the mammalian cell, and cell toxicity. ${ }^{161}$ These drawbacks could be overcome by delivering the gene in chitosan particles, which act as a nonviral carrier. ${ }^{162,163}$ Treatment of diseases, caused by a genetic defect, is the target for gene-loaded chitosan nanoparticles. Nanoparticles loaded with siRNA, especially when prepared using naturally occurring, positively charged chitosan of high molecular weight and degree of acetylation exhibited higher stability, easy adsorption onto the cell surface, and protection and maintenance of the activity of the loaded siRNA gene, resulting in enhanced effectiveness of gene silencing. ${ }^{163}$ Nevertheless, the gene transfection efficacy remains low and needs further improvement.

Chitosan and its derivatives have been studied as an efficient nonviral vector involved in plasmid DNA delivery. ${ }^{157-164}$ The chemically modified chitosan derivatives have been reported to improve chitosan transfection efficiency without affecting its biodegradability and biocompatibility. Nanoparticles prepared with chitosan of a specific degree of deacetylation and ligand-mediated cell uptake chitosan nanoparticles have illustrated enhancement in cell internalization and transfection efficiency. ${ }^{164-167}$ Galactose, transferrin, folate, and mannose are common cell-specific ligands that promote cell uptake through receptor-mediated endocytosis. Transferrin receptor is a universal ligand as it is found on many mammalian cells. ${ }^{165}$ Folate is overexpressed on macrophage surface as well as many human cancer cell surfaces, ${ }^{166}$ whereas galactose ligand modification has been shown to target HepG2 cells through its interaction with asialoglycoprotein receptors. ${ }^{164}$ Plasmid DNA-loaded chitosan nanoparticles were successfully formulated and showed transgene expression that was nearly equivalent to those of the two marketed products, Lipofectamine ${ }^{\mathrm{TM}}$ and FuGENE ${ }^{\circledR} 6 .{ }^{167}$ Mansouri et al ${ }^{168}$ tried to improve the rate of gene transfection by formulation of folic acid-chitosan-DNA nanoparticles. Incorporation of folic acid did not affect the properties of the particles and has promoted internalization of DNA into the cell through the membrane receptors both in vitro and in vivo. The incorporation of DNA into the nanoparticles permitted the preservation of the molecule, 
which was demonstrated to be intact within the carrier. Lower cytotoxicity against HEK 293 cell and good condensation of the loaded DNA were also observed, eliciting the potential of this system as a nonviral DNA vector.

The most important benefit of chitosan modification is the active targeting of the loaded therapeutic agent, which could be accomplished through chemical modification. Self-assembled chitosan-doxorubicin conjugate was prepared using succinic anhydride as a cross-linker, then the monoclonal antibody, trastuzumab, was conjugated to the chitosan-doxorubin conjugate nanoparticles that showed enhanced drug targeting by selective uptake of doxorubicin by Her2+ cancer cells when compared to either unmodified chitosan nanoparticles or free drug. ${ }^{169} \mathrm{~N}$-Caproyl chitosan nanoparticles, whose surface was chemically modified with glycyrrhizin by acylation of the chitosan amino group, were synthesized and effectively delivered in a targeted manner the chemotherapeutic agent, adriamycin, to the hepatocytes. ${ }^{170}$ The hydrophobic moiety, cholanic acid, was used to modify the nanosized cisplatin-loaded glycol chitosan drug delivery system that released the drug in a controlled manner for 1 week, and the prepared system showed a tumor-targeting ability in tumor-bearing mice with higher antitumor effect and lower side effects when compared to free cisplatin. ${ }^{171}$ The same finding was reported for the anticancer agent camptothecin, using the same system, glycol chitosan, in human breast cancer cells. ${ }^{172}$ Avidin and biotin were used to form a complex with chitosan during the preparation of resveratrol chitosan nanoparticles to target the liver and hepatoma cells, the effect which results in enhancing the drug antioxidant and anticancer activity and minimizing the toxicity and side effects. ${ }^{173}$

According to the route of administration, considerable researches have focused on the application of chitosan micro-/nanoparticles as a potential drug delivery system for parenteral and nonparenteral routes, such as oral, nasal, ocular, pulmonary, topical, and transdermal. The research findings of this review are illustrated in the following sections.

\section{Parenteral route of administration}

In practice, parenteral administration refers to introduction into the body of product(s) that are implanted, injected, or infused into blood vessels, tissue spaces, or body compartments. From the site of administration, the drug is then transported to the site of action. Since the administration procedure involves puncture or incision of the body, parenteral route is considered an invasive route of drug administration. Intradermal (ID), subcutaneous (SC), intramuscular (IM), intravenous (IV), and intra-arterial are the common routes of parenteral administration. Figure 6 shows these routes.

The size, surface charges, and hydrophilic/hydrophobic nature of the prepared particles control the IV parenteral administration and biodistribution. ${ }^{174}$ Particles in the nanosize range are easily administered by IV route, because the smallest body microvessels are in the range 5-10 $\mu \mathrm{m}$ in diameter. Following IV administration of nanoparticles, the reticuloendothelial system (RES) in the spleen, lung, liver, and bone marrow entraps particles greater than $100 \mathrm{~nm}$, whereas those of smaller size are characterized

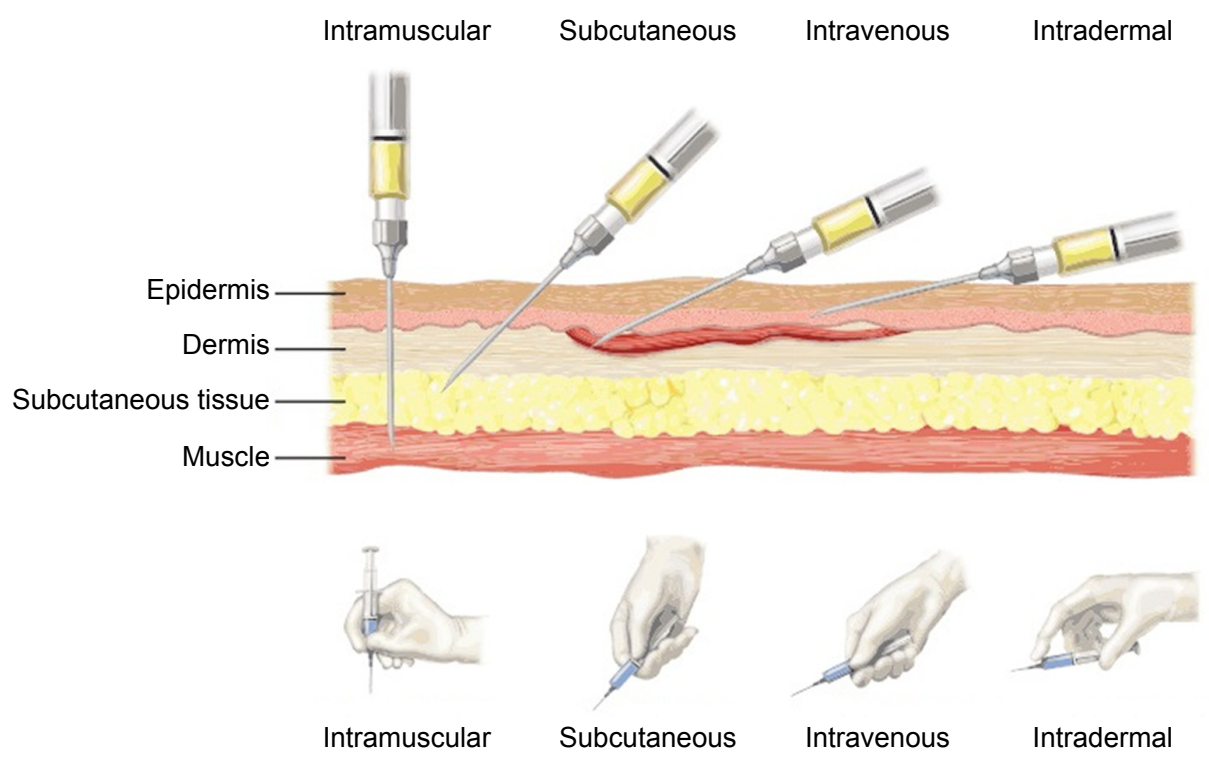

Figure 6 Structure of the skin and subcutaneous layers and common routes of parenteral drug administration. 
by prolonged circulation time. ${ }^{175}$ Although many attempts have been made to illustrate the effect of nanoparticles' surface charges on pharmacokinetics and tissue distribution, the controversy remains, and no clear interpretation has been reported. Hydrophobic particles easily penetrate into the tissues, which is not the case for hydrophilic ones. On the contrary, nanoparticles that are hydrophilic, even through coating with PEG or surfactants of nonionic type, and additionally, smaller than $100 \mathrm{~nm}$, will bypass the phagocytosis performed by macrophages. Coating the prepared particles by PEG - PEGylation - has been reported to prolong the circulation time and avoid entrapment in the RES. Several attempts have been studied to use other polymers such as poloxamers, polyvinyl alcohol, and polysaccharides, yet PEGylation is still the effective and widely used technique. ${ }^{176}$ There are two types of conformation for the process of PEG covering the nanoparticle surface - mushroom conformation at low PEGylation and brush conformation, which is formed when PEGylation is increased to a certain high level. The latter is the ideal mode to protect nanoparticles from serum absorption. PEGylation reduces opsonization, the process of binding of a specific serum protein to a substance that facilitates uptake of this serum protein substance-binding complex by RES, and so prevents recognition of the nanoparticles by the cells of the RES and allows nanoparticles to remain in the blood pool. ${ }^{177}$ In addition to the IV route, but still in the parenteral route, nanoparticles are possibly administered by the subcutaneous and intramuscular routes.

Different drugs in the form of chitosan particles have been administered by the parenteral route and showed enhanced pharmacological effects and reduction in systemic toxicity. IV administration of doxorubicin chitosan nanoparticles illustrated marked regression in tumor growth and improved survival rate in experimental animal. ${ }^{175}$ Patel et a ${ }^{178}$ studied the pharmacokinetic and tissue distribution of doxorubicin chitosan nanoparticles after IV injection and reported enhanced drug distribution to the RES and lower drug systemic toxicity and cardiotoxicity. Paclitaxel was successfully loaded into modified chitosan carrier that has been administered by IV route, and this chitosan carrier system was reported to be less toxic and was characterized by increased tolerated dose when compared to commercial drug formulation. ${ }^{179}$

\section{Nonparenteral routes of administration}

Nonparenteral routes of drug administration have tremendous advantages over injections. These routes represent alternatives for those drugs that cannot be delivered or for patients suffering problems associated with parenteral administration. Variation of serum drug concentration and high plasma concentration, problems often noticed with IM and IV administration, can be overcome by long-term transdermal delivery system. Bypassing the hepatic firstpass metabolism and prevention of the GIT degradation are advantages of the transdermal and transmucosal systems. Intranasal, ocular, buccal/sublingual, pulmonary, topical, and transdermal routes are the most promising, noninvasive systemic delivery options.

\section{Oral route}

Drugs administered orally must survive different $\mathrm{pH}$ and numerous GIT secretions such as potentially degrading enzymes. The process of oral drug absorption involves transport across the GIT membrane via passive diffusion, carrier-mediated transport, or pinocytosis. Carrier-mediated transport may be active transport or facilitated diffusion. In general, the process is affected by some GIT physiological factors, although physicochemical and formulation factors related to the administered drug and dosage account for some effects. Surface area of the absorption site, $\mathrm{pH}$ of the GIT fluids, blood perfusion, natural GIT secretions, and gastric emptying rate are the most important physiological factors. The oral mucosa is characterized by a thin epithelium and rich vascularity, which is a good place for buccal and sublingual administration. Although the stomach has a large epithelial surface, its thick mucous membrane, the effect of the gastric juice and food content on the administered drug, and gastric emptying rate may affect or even limit drug absorption. Perhaps the most important site for drug absorption in the GIT is the small intestine; because of its large surface area, high blood perfusion, its membrane being more permeable than that of the stomach, and wide $\mathrm{pH}$ range. ${ }^{180}$

Drug delivery via the oral route is considered the easiest and the most convenient for patients. Therefore, great attention has been focused on this route for the enhancement of the oral bioavailability, particularly for those drugs presenting GIT problems. The mucoadhesive nature, protection of labile drugs from GIT enzymatic degradation, and the enhancement of absorption of the administered therapeutic agent without damaging the biological system, all result in prospective applications of the chitosan micro-/nanoparticles as oral delivery systems. Chitosan micro-/nanoparticles demonstrated benefits in the treatment of both local GIT and systemic diseases. Intestinal disinfection, suppression of Helicobacter pylori, and treatment of ulcerative colitis are 
examples of local GIT conditions following treatment with chitosan particles loaded with antibiotics. Amoxicillin and clarithromycin have been loaded into chitosan particles and showed local GIT effect for eradication of $H$. pylori. ${ }^{181,182}$ The mucoadhesive properties of chitosan have resulted in prolonged delivery of acyclovir, an antiviral agent, with considerable oral bioavailability improvement due to enhanced retention of the drug in the upper GIT following administration of acyclovir chitosan microspheres. ${ }^{183}$ Protection against GIT degradation, enhancement of bioadhesion, and improvement of oral bioavailability of insulin have also been reported following encapsulation into chitosan microspheres. ${ }^{184}$

Drug colon targeting is useful for treatment of some diseases such as irritable bowel syndrome, ulcerative colitis, and Crohn's disease. Chitosan-based delivery systems have been reported to protect the loaded drugs, such as insulin, from degradation in the upper GIT and, therefore, release these drugs at the colon because of degradation of the chitosan glycosidic linkage by the specific microflora of the colon. ${ }^{185}$ Chitosan microspheres coated with cellulose acetate butyrate and loaded with 5-aminosalicylic acid (5-ASA) have been developed for treatment of ulcerative colitis in which the bioadhesion character of the microspheres was significantly increased by increasing the molecular weight of chitosan and decreasing the coating content. ${ }^{186}$ Furthermore, localization of 5-ASA in the colon and low drug systemic bioavailability were reported after oral administration of 5-ASA-loaded chitosan-Ca-alginate microparticles to Wistar male rats. ${ }^{187}$ Although chitosan is highly soluble in the acidic medium, which results in drug burst in the stomach, coating of the prepared particles with $\mathrm{pH}$-sensitive polymers such as Eudragit S-100 and L-100 was successfully used to overcome this problem, with drugs such as prednisolone, ${ }^{188}$ satranidazole, ${ }^{189}$ and metronidazole. ${ }^{190}$

\section{Nasal route}

The mucosa of the nasal cavity is thin and well vascularized, and so the administered drug can be transferred into the systemic circulation quickly. Other advantages of drug delivery via this route are the avoidance of the hepatic first-pass metabolism and the possibility of systemic and local effect. Limitations for this route include the limited volume of the administered formulation, which restricts the application for potent drugs, and also it is not suitable for long-term or frequently administered drugs because of the harmful effect on the nasal epithelium. ${ }^{191}$ Drugs of low and high molecular weight have been successfully delivered using this route, steroids, antiasthmatic, anesthetics, antihistaminic, antiemetic, sedatives, antimigraine, peptides, peptide analogs such as desmopressin, hormones, vaccines, and most recently drug delivery to the brain for primary meningoencephalitis. ${ }^{192,193}$

The process of drug delivery via the nasal route is challenging due to the short residence time of the drug, high nasal secretion rate, and low permeability of the nasal membrane. Drug physicochemical properties such as surface charges, hydrophilicity/hydrophobicity, partition coefficient, degree of ionization, and molecular size are very important factors that could affect the drug transport by this route. ${ }^{194}$ Different nasal drug delivery systems have been studied and illustrated a potential application in this field. Among those, chitosan particles demonstrated some achievement in the nasal delivery of proteins, vaccines, and other therapeutic agents. The mucoadhesive properties accompanied with the small particle size facilitate both retention and permeation of the administered drug-loaded particles. Insulin-loaded chitosan micro- and nanoparticles showed a considerable decrease in blood glucose level after their nasal administration into rats and rabbits, respectively. ${ }^{195,196}$ Chitosan nanoparticles adsorbed with ovalbumin and cholera toxins induced systemic immune response in rats and were effective for targeting to nasal-associated lymphoid tissues in nasal vaccine delivery. ${ }^{157}$ Induction of IgA antibodies at different mucosal sites in the body such as upper and lower respiratory tract, and small and large intestine as a result of the distribution of the intranasal administered antigen-loaded chitosan particles have been reported. ${ }^{197-199}$ Mice that were intranasally immunized with chitosan microspheres loaded with Bordetella bronchiseptica antigens showed significantly higher $B$. bronchiseptica-specific IgA antibody responses in saliva and serum, with high mice survival rate. ${ }^{197,198}$

\section{Ocular route}

Anatomically, the eye can be divided into two main parts - anterior and posterior. The former region comprises approximately one-third of the eye and consists of cornea, conjunctiva, aqueous humor, iris, ciliary body, and lens, while the latter includes the sclera, choroid, retinal pigment epithelium, neural retina, optic nerve, and vitreous humor. Glaucoma, cataract, allergic conjunctivitis, and anterior uveitis are common diseases affecting the anterior part, whereas diabetic retinopathy and age-related macular degeneration are prevalent diseases of the posterior part. Diseases affecting the anterior eye segment are usually 
treated using topical instillation of conventional ophthalmic dosage forms such as eye drops, but it is difficult to achieve effective drug concentration in the posterior part because of tear turnover, reflex blinking, nasolachrymal drainage, ocular static, and dynamic barriers that resist access/ permeation of the administered drug to deeper segment, and, therefore, less than 5\% of topically applied drug dose reaches the deeper ocular tissues. ${ }^{200}$ Nanoparticle-based ophthalmic formulations are currently of high interest for both anterior and posterior-segment drug delivery because of low irritation, ocular biocompatibility, and convenient bioavailability.

The prolonged ocular residence time, due to mucoadhesiveness, and the absorption-promoting effect of the chitosan nanoparticles compared to the conventional ophthalmic preparations contribute to an improvement of drug ocular efficacy and bioavailability. $\beta$-blockers, antibiotics, anti-inflammatory, and antiallergic drugs are common categories of therapeutic agents loaded into chitosan nanoparticles. These nanoparticles improved the delivery of cyclosporin A, selected as a model drug for treatment of local eye disease, for the ocular mucosa in which the in vitro release data illustrated fast drug release in the first hour, followed by a gradual slow-release stage lasting for 24 hours. $^{201}$ Dorzolamide $\mathrm{HCl}$ and timolol maleate, drugs used for treatment of glaucoma, have been loaded into hyaluronic acid-modified chitosan nanoparticles, and the prepared nanoparticles potentially improved the mucoadhesiveness and significantly reduced the intraocular pressure compared to plain drug solution. ${ }^{202}$

Recently, chitosan and its derivatives have been studied as a nonviral vector for retinal gene therapy. Ultrapure oligochitosans polyplexes have been prepared, characterized, and were reported to be efficient in protecting the incorporated plasmid against enzymatic digestion and transfection efficiency. ${ }^{203}$ Chitosan-DNA nanoparticles based on ultrapure chitosan oligomers are another example that have been recently marketed and used as carriers for nonviral gene therapy. It has been mentioned that these newly developed nanoparticles, ultrapure chitosan-DNA nanoparticles, could be examined for the treatment of various ocular diseases outside the cornea and for different gene therapy applications. ${ }^{204}$ In another study, a novel hyaluronan-chitosan nanocarrier-loaded DNA has been developed for topical ophthalmic gene therapy. The prepared nanoparticles were considered an efficient tool for delivery of the loaded plasmid DNA into the cells through reaching significant transfection levels and so was mentioned to be a new strategy toward gene therapy for various ocular diseases. ${ }^{205}$

\section{Pulmonary route}

Owing to the large absorptive surface area (up to 70-140 $\mathrm{m}^{2}$ ), thin alveolar absorptive mucosal membrane (100-200 nm), and good blood supply due to the highly vascularized extensive capillary network, the pulmonary route can be used to administer drugs. ${ }^{206}$ Low enzymatic activity and avoiding first-pass metabolism are other advantages of this route. So, growing attention has been given to the pulmonary route as a noninvasive pathway for both systemic and local drug delivery. These include topical treatment of lung infections, pulmonary hypertension, and asthma and systemic administration of hormones, peptides, and proteins such as insulin, oxytocin, and growth hormone. ${ }^{207}$ The lung is composed of two regions namely conducting airways and the respiratory region. The airway is divided into nasal cavity and associated sinuses, pharynx, larynx, trachea, bronchi, and bronchioles, while the respiratory region consists of respiratory bronchioles, alveolar ducts, and alveolar sacs. Drug absorption from the upper airways is limited due to low blood supply, small surface area, the high filtering function of this part that can remove up to $90 \%$ of the administered drug, and the viscous mucus that coats the wall of the airway and expels foreign substance upward and out of the lung by the action of the ciliated cells present in this region. ${ }^{208}$ Other obstacles that control the transport of drug from this route are the size of pores and tight junction depth of alveolar and endothelial cells and the pulmonary blood-gas barrier system. ${ }^{209}$

Administration of drugs through this route could be achieved through intranasal or oral inhalation. The narrow lumen airway of the former limit the drug delivery compared to the latter, which allows administration of very small particles even in low concentration. The particle size, shape, and surface electrical charges of the administered drug particles influence drug diffusion through this route. ${ }^{210}$ Small-sized particles diffuse rapidly based on the Brownian motion. Alveolar macrophages are predominantly responsible for nanoparticles clearance through phagocytosis of the administered particles. Macrophages that entrap the particles are then moved toward the mucociliary escalator to start the clearance process. Several studies reported the inefficiency of the alveolar macrophages to phagocytose ultrafine particles, and so these particles are not cleared in the alveolar region. ${ }^{211}$ In this case, toxicity is a consequence of the long-term accumulation of these particles in the lung. 
Nanoparticles of chitosan and its derivatives were studied for pulmonary administration of some drugs to treat different pulmonary diseases ${ }^{212}$ and infections such as tuberculosis. ${ }^{213,214}$ The biocompatibility of chitosan nanoparticles administered as respirable powder was evaluated by Grenha et $\mathrm{al}^{215}$ using human respiratory epithelial Calu-3 and A549 cell lines, and the results demonstrated the mucoadhesive feature of the chitosan particles, no signs of overtoxicity, and no change in transepithelial electrical resistance or solute permeability. Both Calu-3 and A549 respiratory epithelial cell lines have been previously used to evaluate the in vitro efficacy and safety of particulate drug delivery systems. Calu-3 cell layers form tight junctions in vitro and, under suitable culture conditions, exhibit acceptable in vivo-like barrier properties. ${ }^{215}$ Inhalation of chitosan microparticles has been reported to be of potential interest in pulmonary pharmacotherapy as indicated by the inflammation response produced in rat lungs, which was 1.8fold greater in the group administered microparticles than the control group without chitosan microparticles. These effects were documented by an increase in bronchoalveolar lavage fluid protein and lactate dehydrogenase activity and also with an increase in lung tissue myeloperoxidase activity and leukocyte migration. ${ }^{216}$ Intratracheal instillation of hydrophobically modified glycol chitosan nanoparticles to mice exhibited rapid uptake into systemic circulation and induced transient neutrophilic pulmonary inflammation in the tested animals from 6 hours to 3 days after instillation. ${ }^{217}$ So, chitosan micro- and nanoparticles could be considered successful vehicles for pulmonary drug delivery. Recently, chitosan/carrageenan/tripolyphosphate nanoparticle-loaded BSA were prepared using spray drying technique to meet the required geometric diameter and mass density and aerodynamic character essential to pulmonary drug delivery and were evaluated for their capacity as protein carrier for nasal and pulmonary transmucosal delivery. A biocompatibility study was also conducted on Calu-3 and A549 cells, respiratory cell lines, in which no inflammatory response or change in the transepithelial electrical resistance of the cell lines were noticed. ${ }^{218}$

\section{Topical and transdermal routes}

Physiologically, the skin is composed of four layers stratum corneum, epidermis, dermis, and subcutaneous tissue. In addition to these layers, several pilosebaceous and sweat glands are dispersed throughout the skin. Although the skin has relatively a large surface area, it acts as a penetration barrier that represents a challenge for the delivery of any therapeutic agent, either into the skin strata regarding topical application or into the systemic circulation through transdermal application. This barrier function is mainly due to the stratum corneum, the outer most layer of the epidermis, which consists of aggregated keratin filaments covered with a cornified envelope surrounded by multiple lamellar lipid bilayer. This structure prevents both excessive water loss from the body and entry of topically applied drugs, which represents challenge for drugs applied for local or systemic effect. Drugs of low molecular weight and macromolecules have been formulated as topical and transdermal delivery systems, and many systems are undergoing clinical trials. ${ }^{219}$ Skin permeation of the administered drug may be accomplished by intercellular or transcellular penetration of the stratum corneum layer, or across hair follicles, sebaceous glands, and sweat glands. Substances smaller than $500 \mathrm{kDa}$ that exhibit sufficient oil solubility and high partition coefficient are absorbed easily through the skin. However, in contrast, larger drug molecules (molecular weight $>500 \mathrm{kDa}$ ) cannot pass the skin cutaneous barrier. ${ }^{220}$ Topical and transdermal routes offer many advantages compared to the other drug delivery routes. Transdermal is a noninvasive, inexpensive, and self-administered drug delivery system that provides extended drug-release effect without significant first-pass effect, whereas the topical route allows direct application of the drug to the site of action with minimal risk of systemic side effect.

Chitosan nanoparticles have been extensively used in topical as well as transdermal drug delivery. Retinol, a derivative of vitamin $\mathrm{A}$, has been encapsulated in chitosan nanoparticles and was efficiently used in the treatment of acne and wrinkles. ${ }^{221}$ Fabrication of acyclovir-loaded chitosan nanoparticles leads to a decrease in the photodegradation of the drug, thus contributing to increased drug stability and an improvement in drug penetration through porcine skin. 222 Delivery of macromolecules such as plasmid DNA and antisense oligonucleotides previously loaded into chitosan nanoparticles has been reported. Suppression of $\beta$-gal expression following administration of antisense oligonucleotides at 6 days posttransfection in rats has also been demonstrated. ${ }^{223}$ Transfection of DNA in baby rat skin subsequent to topical application of DNA-chitosan nanoparticles was also described by the same authors. ${ }^{224}$

Generally speaking, nonparenteral routes of therapeutic administration have gained intense interest, especially for the administration of macromolecules such as peptides, proteins, hormones, and antigens. Chitosan and its derivatives have been extensively used for mucosal as 
well as parenteral biotherapeutics delivery owing to the mucoadhesive properties and enhanced local and systemic therapeutic effect. The size of the prepared particles, which could be controlled through the processing and formulation parameters, is pivotal for the efficient delivery of the loaded substances.

\section{Chitosan metal nanoparticles}

Metal nanoparticles of copper $(\mathrm{Cu})$, silver $(\mathrm{Ag})$, and gold $(\mathrm{Au})$ have demonstrated a wide spectrum of activity against gram-negative and gram-positive bacteria as well as fungi. However, there are great concerns about the human and environmental safety of these metal nanoparticles. In addition, the stability of these particles is also under discussion, especially regarding copper nanoparticles, which undergo rapid oxidation upon exposure to the air. ${ }^{225}$ Synthesis of these metal nanoparticles in the presence of biocompatible polymers (such as PEG, polyvinyl pyrrolidone, and chitosan) and surfactants that are used as stabilizers could help overcome these limitations. The coating of the particles' surface using polymeric materials, such as chitosan, has been reported to enhance the antimicrobial activity of these particles, ${ }^{225}$ owing to chitosan antimicrobial activity.

Chitosan-coated silver nanoparticles were prepared by a chemical reduction method and have reported in applications as a biosensor and in cancer therapy. The prepared nanoparticles exhibited biodegradable character, good antimicrobial activity, and prolonged action of silver on the affected cells. ${ }^{226}$ Honary et $\mathrm{al}^{227}$ synthesized chitosan-coated silver nanoparticles by the same method and by utilizing chitosans of different molecular weight. The authors demonstrated that the nanoparticle characteristics were influenced by the molecular weight of chitosan, as well as by the process conditions, such as stirring speed and temperature. They also mentioned that higher antibacterial activity against Staphylococcus aureus was achieved with smaller particle size due to the increase in the particle surface area.

Gold nanoparticles have been reported to be useful in diagnosis and drug delivery. The incorporation of chitosan during the synthesis of these metal nanoparticles offers better penetration and uptake of therapeutic agents such as insulin, across the mucosal membrane, and chitosan itself acts as a reducing agent during gold nanoparticle synthesis. ${ }^{228}$ The prepared insulin-loaded chitosan gold nanoparticles were stable, did not show any sign of aggregation for 6 months, and significantly lowered the blood glucose level in diabetic rats following oral and nasal administration. ${ }^{228}$ Recently,
Salehizadeh et $\mathrm{al}^{229}$ mentioned the formation of $\mathrm{Fe}_{3} \mathrm{O}_{4}-$ gold-chitosan nanostructure by the chemical coprecipitation method and reported the usefulness of the prepared nanoparticles in different biotechnological and biomedical applications.

Chitosan copper-loaded nanoparticles were prepared by ionic gelation between chitosan and TPP and showed a marked growth inhibition of a wide range of microorganisms, such as S. aureus, Salmonella typhimurium, Salmonella choleraesuis, and Escherichia coli, in which the minimum inhibitory concentration was less than $0.25 \mu \mathrm{g} / \mathrm{mL} .{ }^{230}$ Green synthesis is the technique widely used to prepare this type of chitosan metal nanoparticles, involving reduction of copper in an aqueous solution of chitosan and an organic acid, such as ascorbic acid, which prevents the formation of copper oxides. $^{231}$

More recently, chitosan cobalt oxide nanoparticles were developed, and their activity on human leukemic cells was investigated. ${ }^{232}$ The authors demonstrated increase in the reactive oxygen species and caspase activation following exposure of the leukemic cells to these chitosan-coated metallic nanoparticles, effects that are known to lead to cancer cell death. Therefore, there is an indication of the potential of these nanoparticles for an application in cancer therapy.

\section{Conclusion}

This review shows that extensive research activities have been focused on the applications of chitosan-based microand nanoparticles. Successful loading and delivery of different molecules, including low-molecular-weight drugs and macromolecules, such as proteins, peptides, vaccines, hormones, and genes by these systems via different routes of administration, find potential therapeutic applications. The development of chitosan derivatives has extended these applications due to the enhancement of bioavailability accomplished by an increase in the stability, solubility, mucoadhesiveness, cellular permeability, absorption, biodistribution, and tissue targeting achieved when particulate carriers are based on these derivatives. This review has addressed the different techniques that could be utilized in the development of these particulate systems and methods of characterization of the obtained particles. An overview on the parenteral and nonparenteral applications of these chitosan and chitosan derivatives-based particulate system has been illustrated. Chitosan-metal nanoparticles are another type of particle that has demonstrated the ability to improve antimicrobial and pharmacodynamic activity when compared with metal nanoparticles devoid of chitosan coating. 


\section{Future challenges}

Gene transfection efficiency for gene-loaded polymeric nanoparticles, such as chitosan, remains the most challenging in the development of most polymer-based nanoparticles for gene delivery. Although some researchers have made several attempts in this area, as illustrated in this review, the rate of transfection still remains low. Moreover, currently, several drugs of plant origin, especially those possessing antitumor activity, are being discovered and the process of loading these therapeutic agents into a suitable carrier and targeting to the active site of action needs improvement. Finally, although that chitosan particulate systems have been studied for more than 2 decades, always with good results and promise in delivery of different therapeutic agents, both in vitro and in vivo in experimental animals, no commercial formulations of these systems are available. This could be attributed to poor bioavailability, possible immunogenicity and long-term toxicity, low target specificity, limited stability, and lack of clinical trials in human, and these items need further investigation.

\section{Acknowledgments}

The authors gratefully acknowledge Dr Ana Grenha for her guidance. The authors also thank Dr Mohammed M Badran for his collaboration in the scanning electron microscope study.

\section{Disclosure}

The authors report no conflict of interest in this work.

\section{References}

1. Chirra HD, Desai TA. Emerging microtechnologies for the development of oral drug delivery devices. Adv Drug Deliv Rev. 2012;64(14): $1569-1578$.

2. Des Rieux A, Fievez V, Garinot M, Schneider YJ, Preat V. Nanoparticles as potential oral delivery systems of proteins and vaccines: a mechanistic approach. J Control Release. 2006;116(1):1-27.

3. Sahoo SK, Parveen S, Panda JJ. The present and future of nanotechnology in human health care. Nanomedicine. 2007;3(1):20-31.

4. Park JH, Lee S, Kim JH, Park K, Kim K, Kwon IC. Polymeric nanomedicine for cancer therapy. Prog Polym Sci. 2008;33(1):113-137.

5. Sumer B, Gao J. Theranostic nanomedicine for cancer. Nanomedicine. 2008;3(2):137-140.

6. Dass CR, Choong P. The use of chitosan formulations in cancer therapy. J Microencapsul. 2008;25(4):275-279.

7. Prabaharan M. Review paper: chitosan derivatives as promising materials for controlled drug delivery. J Biomater Appl. 2008;23(1):5-36.

8. Augst AD, Kong HJ, Mooney DJ. Alginate hydrogels as biomaterials. Macromol Biosci. 2006;6(8):623-633.

9. Gombotz WR, Wee SF. Protein release from alginate matrices. $A d v$ Drug Deliv Rev. 1998;31(3):267-285.

10. Piyakulawat P, Praphairaksit N, Chantarasiri N, Muangsin N. Preparation and evaluation of chitosan/carrageenan beads for controlled release of sodium diclofenac. AAPS PharmSciTech. 2007; 8(4):E97.
11. Santo VE, Frias AM, Carida M, et al. Carrageenan-based hydrogels for the controlled delivery of PDGF-BB in bone tissue engineering applications. Biomacromolecules. 2009;10(6):1392-1401.

12. Grenha A, Gomes ME, Rodrigues M, et al. Development of new chitosan/carrageenan nanoparticles for drug delivery applications. J Biomed Mater Res A. 2010;92(4):1265-1272.

13. Agnihotri SA, Mallikarjuna NN, Aminabhavi TM. Recent advances on chitosan-based micro- and nanoparticles in drug delivery. J Control Release. 2004;100(1):5-28.

14. Roberts GAF. Structure of chitin and chitosan. In: Roberts GAF, editor. Chitin Chemistry. Houndmills, Basingstoke: Macmillan; 1992:1-53.

15. LeHoux JG, Grondin F. Some effects of chitosan on liver function in the rat. Endocrinology. 1993;132:1078-1084.

16. Chandy T, Sharma CP. Chitosan - as a biomaterial. Biomater Artif Cells Artif Organs. 1990;18(1):1-24.

17. Sugano M, Watanabe S, Kishi A, Izume M, Ohtakara A. Hypocholesterolemic action of chitosans with different viscosity in rats. Lipids. 1988;23(3):187-191.

18. Azad AK, Sermsintham N, Chandrkrachang S, Stevens WF. Chitosan membrane as a wound-healing dressing: characterization and clinical application. J Biomed Mater Res B Appl Biomater. 2004;69(2):216-222.

19. Felt O, Buri P, Gurny R. Chitosan: a unique polysaccharide for drug delivery. Drug Dev Ind Pharm. 1998;24(11):979-993.

20. Rabea EI, Badawy ME, Steurbaut W, et al. Fungicidal effect of chitosan derivatives containing an N-alkyl group on grey mould Botryti77s cinerea and rice leaf blast Pyricularia grisea. Commun Agric Appl Biol Sci. 2005;70(3):219-223.

21. Kockisch S, Rees GD, Young SA, Tsibouklis J, Smart JD. Polymeric microspheres for drug delivery to the oral cavity: an in vitro evaluation of mucoadhesive potential. J Pharm Sci. 2003;92:1614-1623.

22. Sinha VR, Singla AK, Wadhawan S, et al. Chitosan microspheres as a potential carrier for drugs. Int J Pharm. 2004;274(1-2):1-33.

23. Huo M, Zhang Y, Zhou J, et al. Synthesis and characterization of lowtoxic amphiphilic chitosan derivatives and their application as micelle carrier for antitumor drug. Int J Pharm. 2010;394(1-2):162-173.

24. Dasha M, Chiellinia F, Ottenbriteb RM, Chiellini E. Chitosan - a versatile semi-synthetic polymer in biomedical applications. Prog Polym Sci. 2011;36:981-1014.

25. Calderón L, Harris R, Cordoba-Diaz M, et al. Nano and microparticulate chitosan-based systems for antiviral topical delivery. Eur J Pharm Sci. 2013;48(1-2):216-222.

26. Aiedeh K, Taha MO. Synthesis of chitosan succinate and chitosan phthalate and their evaluation as suggested matrices in orallyadministered, colon-specific drug delivery systems. Arch Pharm (Weinheim). 1999;332(3):103-107.

27. Florea BI, Thanou M, Geldof M, Meaney C, Junginger HE, Borchard G. Modified chitosan oligosaccharides as transfection agents for gene therapy of cystic fibrosis. Proc Int Symp Control Release Bioact Mater. 2000;27:846-847.

28. Sieval AB, Thanou M, Kotze AF, Verhoef JE, Brussee J, Junginger HE. Preparation and NMR characterization of highly substituted N-trimethyl chitosanchloride. Carbohydr Polym. 1998;36:157-165.

29. Verheul RJ, Amidi M, van der Wal S, van Riet E, Jiskoot W, Hennink WE. Synthesis, characterization and in vitro biological properties of O-methyl free N,N,N-trimethylated chitosan. Biomaterials. 2008;29:3642-3649.

30. Hamman JH, Stander M, Kotze AF. Effect of the degree of quaternisation of N-trimethyl chitosan chloride on absorption enhancement: in vivo evaluation in rat nasal epithelia. Int J Pharm. 2002;232:235-242.

31. Thanou M, Verhoef JC, Marbach P, Junginger HE. Intestinal absorption of octreotide: N-trimethyl chitosan chloride (TMC) ameliorates the permeability and absorption properties of the somatostatin analogue in vitro and in vivo. J Pharm Sci. 2000;89:951-957.

32. Thanou M, Nihot MT, Jansen M, Verhoef JC, Junginger HE. Mono-Ncarboxymethyl chitosan (MCC), a polyampholytic chitosan derivative, enhances the intestinal absorption of low molecular weight heparin across intestinal epithelia in vitro and in vivo. J Pharm Sci. 2001; 90:38-46. 
33. Xu Y, Du Y, Huang R, Gao L. Preparation and modification of N-(2-hydroxyl) propyl-3-trimethyl ammonium chitosan chloride nanoparticle as a protein carrier. Biomaterials. 2003;24:5015-5022.

34. Bernkop-Schnurch A, Hornof M, Zoidl T. Thiolated polymers-thiomers: synthesis and in vitro evaluation of chitosan-2-iminothiolane conjugates. Int J Pharm. 2003;260:229-237.

35. Hornof MD, Kast CE, Bernkop-Schnurch A. In vitro evaluation of the viscoelastic properties of chitosan-thioglycolic acid conjugates. Eur J Pharm Biopharm. 2003;55:185-190.

36. Roldo M, Hornof M, Caliceti P, Bernkop-Schnurch A. Mucoadhesive thiolated chitosans as platforms for oral controlled drug delivery: synthesis and in vitro evaluation. Eur J Pharm Biopharm. 2004;57: 115-121.

37. Yin L, Ding J, He C, Cui L, Tang C, Yin C. Drug permeability and mucoadhesion properties of thiolated trimethyl chitosan nanoparticles in oral insulin delivery. Biomaterials. 2009;30(29):5691-5700.

38. Ubaidulla U, Khar RK, Ahmad FJ, Sultana Y, Panda AK. Development and characterization of chitosan succinate microspheres for the improved oral bioavailability of insulin. J Pharm Sci. 2007;96(11): 3010-3023.

39. Ubaidulla U, Sultana Y, Ahmed FJ, Khar RK, Panda AK. Chitosan phthalate microspheres for oral delivery of insulin: preparation, characterization, and in vitro evaluation. Drug Deliv. 2007;14(1): 19-23.

40. Rekha MR, Sharma CP. Synthesis and evaluation of lauryl succinyl chitosan particles towards oral insulin delivery and absorption. J Control Release. 2009;135(2):144-151.

41. Tomita M, Hayashi M, Horie T, Ishizawa T, Awazu S. Enhancement of colonic drug absorption by the transcellular permeation route. Pharm Res. 1988;5(12):786-789.

42. Le Tien C, Lacroix M, Ispas-Szabo P, Mateescu MA. N-acylated chitosan: hydrophobic matrices for controlled drug release. J Control Release. 2003;93(1):1-13.

43. Sonia TA, Sharma CP. Chitosan and its derivatives for drug delivery perspective. Adv Polym Sci. 2011;243:23-54.

44. Thanou M, Nihot MT, Jansen M, Verhoef JC, Junginger HE. Mono$\mathrm{N}$-carboxymethyl chitosan (MCC), a polyampholytic chitosan derivative, enhances the intestinal absorption of low molecular weight heparin across intestinal epithelia in vitro and in vivo. J Pharm Sci. 2001;90:38-46.

45. Jayakumar R, Prabaharan M, Reis RL, Mano JF. Graft copolymerized chitosan-present status and applications. Carbohydr Polym. 2005;62: $142-158$.

46. Shanta KL, Harding DRK. Synthesis and characterization of chemically modified chitosan microspheres. Carbohydr Polym. 2002;48: 247-253.

47. Zhang C, Ping Q, Ding Y, Cheng Y, Shen J. Synthesis, characterization and microsphere formation of galactosylated chitosan. J Appl Polym Sci. 2004;91:659-665.

48. Sezer AD, Cevher E. Topical drug delivery using chitosan nano- and microparticles. Expert Opin Drug Deliv. 2012;9(9):1129-1146.

49. Chaudhury A, Das S. Recent advancement of chitosan-based nanoparticles for oral controlled delivery of insulin and other therapeutic agents. AAPS PharmSciTech. 2011;12(1):10-20.

50. Kumari A, Yadav SK, Yadav SC. Biodegradable polymeric nanoparticles based drug delivery systems. Colloids Surf B Biointerfaces. 2010;75:1-18.

51. Rao SB, Sharma CP. Use of chitosan as biomaterial: studies on its safety and hemostatic potential. J Biomed Mater Res. 1997;34:21-28.

52. Lehr CM, Bouwstra JA, Schacht EH, Junginger HE. In vitro evaluation of mucoadhesive properties of chitosan and some other natural polymers. Int J Pharm. 1992;78:43-48.

53. Chowdary KP, Rao YS. Design and in vitro and in vivo evaluation of mucoadhesive microcapsules of glipizide for oral controlled release: a technical note. AAPS PharmSciTech. 2003;4(3):E39.

54. Dastan T, Turan K. In vitro characterization and delivery of chitosanDNA microparticles into mammalian cells. J Pharm Pharm Sci. 2004; 7(2):205-214.
55. Li YH, Fan MW, Bian Z, Chen Z, Zhang Q, Yang HR. Chitosan-DNA microparticles as mucosal delivery system: synthesis, characterization and release in vitro. Chin Med J (Engl). 2005;118(11):936-941.

56. Chua BY, Al Kobaisi M, Zeng W, Mainwaring D, Jackson DC. Chitosan microparticles and nanoparticles as biocompatible delivery vehicles for peptide and protein-based immunocontraceptive vaccines. Mol Pharm. 2012;9(1):81-90.

57. Varshosaz J, Sadrai H, Alinagari R. Nasal delivery of insulin using chitosan microspheres. J Microencapsul. 2004;21(7):761-774.

58. Acikgoz M, Kas HS, Orman M, Hincal AA. Chitosan microspheres of diclofenac sodium: I. Application for factorial design and evaluation of release kinetics. J Microencapsul. 1996;13:141-160.

59. Akbuga J, Bergisadi N. 5-fluorouracil-loaded chitosan microspheres: preparation and release characteristics. J Microencapsul. 1996;13: $161-168$.

60. Wang YH, Sato H, Adachi I, Horikoshi I. Optimisation of the formulation design of chitosan microspheres containing cisplatin. JPharm Sci. 1996;85:1204

61. Ko JA, Park HJ, Hwang SJ, Park JB, Lee JS. Preparation and characterization of chitosan microparticles intended for controlled drug delivery. Int J Pharm. 2002;249(1-2):165-174.

62. Dini E, Alexandridou S, Kiparissides C. Synthesis and characterization of cross-linked chitosan microspheres for drug delivery applications. J Microencapsul. 2003;20(3):375-385.

63. Jansen J, Maibach HI. Encapsulation to deliver topical actives. Handbook of Cosmetic Science and Technology. New York, NY: Marcel Dekker; 2001.

64. Kofuji K, Qian CJ, Murata Y, Kawashima S. Preparation of chitosan microparticles by water-in-vegetable oil emulsion coalescence technique. React Funct Polym. 2005;62:77-83.

65. Giunchedi P, Juliano C, Gavini E, Cossu M, Sorrenti M. Formulation and in vivo evaluation of chlorhexidine buccal tablets prepared using drug-loaded chitosan microspheres. Eur J Pharm Biopharm. 2002;53(2): 233-239.

66. Corrigan DO, Healy AM, Corrigan OI. Preparation and release of salbutamol from chitosan and chitosan co-spray dried compacts and multiparticulates. Eur J Pharm Biopharm. 2006;62(3):295-305.

67. Alhalaweh A, Andersson S, Velaga SP. Preparation of zolmitriptanchitosan microparticles by spray drying for nasal delivery. Eur J Pharm Sci. 2009;38(3):206-214.

68. Li X, Kong X, Shi S, et al. Preparation of alginate coated chitosan microparticles for vaccine delivery. BMC Biotechnol. 2008;8:89.

69. Abreu FOMS, Forte MMC, Kist TBL, Honaiser LP. Effect of the preparation method on the drug loading of alginate-chitosan microspheres. eXPRESS Polym Lett. 2010;4(8):456-464.

70. Zhang Y, Wei W, Lv P, Wang L, Ma G. Preparation and evaluation of alginate-chitosan microspheres for oral delivery of insulin. Eur JPharm Biopharm. 2011;77(1):11-19.

71. Wang Q, Xie X, Zhang X, Zhang J, Wang A. Preparation and swelling properties of $\mathrm{pH}$-sensitive composite hydrogel beads based on chitosang-poly(acrylic acid)/vermiculite and sodium alginate for diclofenac controlled release. Int J Biol Macromol. 2010;46(3):356-362.

72. Krekeler MPS, Guggenheim S. Defects in microstructure in palygorskite-sepiolite minerals: a transmission electron microscopy (TEM) study. Appl Clay Sci. 2008;39(1-2):98-105.

73. Wang Q, Wu J, Wang W, Wang A. Preparation, characterization and drug-release behaviors of crosslinked chitosan/attapulgite hybrid microspheres by a facile spray-drying technique. J Biomater Nanobiotechnol. 2011;2:250-257.

74. Zhang F, Koh GY, Jeansonne DP, et al. A novel solubility enhanced curcumin formulation showing stability and maintenance of anticancer activity. J Pharm Sci. 2011;100(7):2778-2789.

75. Yallapu MM, Gupta BK, Jaggi M, Chauhan SC. Fabrication of curcumin encapsulated PLGA nanoparticles for improved therapeutic effects in metastatic cancer cells. J Colloid Interface Sci. 2010;351(1):19-29.

76. Das RK, Kasoju N, Bora U. Encapsulation of curcumin in alginatechitosan-pluronic composite nanoparticles for delivery to cancer cells. Nanomedicine. 2010;6(1):153-160. 
77. Thangapazham RL, Puri A, Tele S, Blumenthal R, Maheshwari K. Evaluation of a nanotechnology-based carrier for delivery of curcumin in prostate cancer cells. Int J Oncol. 2008;32(5):1119-1123.

78. Guzman-Villanueva D, El-Sherbiny IM, Herrera-Ruiz D, Smyth HD. Design and in vitro evaluation of a new nano-microparticulate system for enhanced aqueous-phase solubility of curcumin. Biomed Res Int. 2013; 2013:724763.

79. Maestrelli F, Garcia-Fuentes M, Mura P, Alonso MJ. A new drug nanocarrier consisting of chitosan and hydoxypropylcyclodextrin. Eur J Pharm Biopharm. 2006;63(2):79-86.

80. Wang J, Tan H, Yu A, et al. Preparation of chitosan-based nanoparticles for delivery of low molecular weight heparin. J Biomed Nanotechnol. 2011;7(5):696-703.

81. Lee SJ, Park K, Oh YK, et al. Tumor specificity and therapeutic efficacy of photosensitizer-encapsulated glycol chitosan-based nanoparticles in tumor-bearing mice. Biomaterials. 2009;30(15):2929-2939.

82. Prabaharan M. Chitosan-based nanoparticles for tumor-targeted drug delivery. Int J Biol Macromol. 2014;72:1313-1322.

83. Kwon IC. Chitosan-based nanoparticles for cancer therapy; tumor specificity and enhanced therapeutic efficacy in tumor-bearing mice. J Control Release. 2008;132(3):e69-e70.

84. Garcia-Fuentes M, Prego C, Torres D, Alonso MJ. A comparative study of the potential of solid triglyceride nanostructures coated with chitosan or poly(ethylene glycol) as carriers for oral calcitonin delivery. Eur $J$ Pharm Sci. 2005;25:133-143.

85. Vila A, Sanchez A, Tobio M, Calvo P, Alonso MJ. Design of biodedegradable particles for protein delivery. J Control Release. 2002;78:15-24.

86. Pan Y, Li YJ, Zhao HY, et al. Bioadhesive polysaccharide in protein delivery system: chitosan nanoparticles improve the intestinal absorption of insulin in vivo. Int J Pharm. 2002;249:139-147.

87. Katas H, Raja MA, Lam KL. Development of chitosan nanoparticles as a stable drug delivery system for protein/siRNA. Int J Biomater. 2013;2013:146320.

88. Gan Q, Wang T. Chitosan nanoparticle as protein delivery carrier systematic examination of fabrication conditions for efficient loading and release. Colloids Surf B Biointerfaces. 2007;59(1):24-34.

89. Cui Z, Mumper RJ. Chitosan-based nanoparticles for topical genetic immunization. J Control Release. 2001;75(3):409-419.

90. Prego C, Paolicelli P, Díaz B, et al. Chitosan-based nanoparticles for improving immunization against hepatitis B infection. Vaccine. 2010; 28(14):2607-2614.

91. Ma Z, Lim TM, Lim LY. Pharmacological activity of peroral chitosan-insulin nanoparticles in diabetic rats. Int J Pharm. 2005; 293(1-2):271-280.

92. Qu JB, Shao HH, Jing GL, Huang F. PEG-chitosan-coated iron oxide nanoparticles with high saturated magnetization as carriers of 10-hydroxycamptothecin: preparation, characterization and cytotoxicity studies. Colloids Surf B Biointerfaces. 2013;102:37-44.

93. Chronopoulou L, Massimi M, Giardi MF, et al. Chitosan-coated PLGA nanoparticles: a sustained drug release strategy for cell cultures. Colloids Surf B Biointerfaces. 2013;103:310-317.

94. Bagre AP, Jain K, Jain NK. Alginate coated chitosan core shell nanoparticles for oral delivery of enoxaparin: in vitro and in vivo assessment. Int J Pharm. 2013;456(1):31-40.

95. Zhang Y, Chan HF, Leong KW. Advanced materials and processing for drug delivery: the past and the future. Adv Drug Deliv Rev. 2013; 65(1):104-120.

96. Luangtana-anan M, Opanasopit P, Ngawhirunpat T, et al. Effect of chitosan salts and molecular weight on a nanoparticulate carrier for therapeutic protein. Pharm Dev Technol. 2005;10:189-196.

97. Chan HK, Kwok PC. Production methods for nanodrug particles using the bottom-up approach. Adv Drug Deliv Rev. 2011;63:406-416.

98. Hennink WE, van Nostrum CF. Novel crosslinking methods to design hydrogels. Adv Drug Deliv Rev. 2002;54(1):13-36.

99. Mao S, Bakowsky U, Jintapattanakit A, Kissel T. Self-assembled polyelectrolyte nanocomplexes between chitosan derivatives and insulin. J Pharm Sci. 2006;95:1035-1048.
100. Ko JA, Park HJ, Hwang SJ, Park JB, Lee JS. Preparation and characterization of chitosan microparticles intended for controlled drug delivery. Int J Pharm. 2002;249:165-174.

101. Vila A, Sánchez A, Janes K, et al. Low molecular weight chitosan nanoparticles as new carriers for nasal vaccine delivery in mice. Eur J Pharm Biopharm. 2004;57(1):123-131.

102. Amidi M, Romeijn SG, Borchard G, Junginger HE, Hennink WE, Jiskoot W. Preparation and characterization of protein-loaded $\mathrm{N}$-trimethyl chitosan nanoparticles as nasal delivery system. $J$ Control Release. 2006;111(1-2):107-116.

103. Amidi M, Romeijn SG, Verhoef JC, et al. N-trimethyl chitosan (TMC) nanoparticles loaded with influenza subunit antigen for intranasal vaccination: biological properties and immunogenicity in a mouse model. Vaccine. 2007;25(1):144-153.

104. Ozbas-Turan S, Akbuga J, Aral C. Controlled release of interleukin-2 from chitosan microspheres. J Pharm Sci. 2002;91:1245-1251.

105. Kizilay E, Kayitmazer AB, Dubin PL. Complexation and coacervation of polyelectrolytes with oppositely charged colloids. Adv Colloid Interface Sci. 2011;167(1-2):24-37.

106. Bozkir A, Saka OM. Chitosan nanoparticles for plasmid DNA delivery: effect of chitosan molecular structure on formulation and release characteristics. Drug Deliv. 2004;11(2):107-112.

107. Mooren FC, Berthold A, Domschke W, Kreuter J. Influence of chitosan microspheres on the transport of prednisolone sodium phosphate across HT-29 cell monolayers. Pharm Res. 1998;15(1): $58-65$.

108. Basu SK, Kavitha K, Rupeshkumar M. Evaluation of ketorolac tromethamine microspheres by chitosan/gelatin B complex coacervation. Sci Pharm. 2010;78:79-92.

109. Sarmento B, Ribeiro A, Veiga F, Ferreira D. Development and characterization of new insulin containing polysaccharide nanoparticles. Colloids Surf B Biointerfaces. 2006;53:193-202.

110. Huang M, Vitharana SN, Peek LJ, Coop T, Berkland C. Polyelectrolyte complexes stabilize and controllably release vascular endothelial growth factor. Biomacromolecules. 2007;8:1607-1614.

111. Lin YH, Chung CK, Chen CT, Liang HF, Chen SC, Sung HW. Preparation of nanoparticles composed of chitosan/poly- $\gamma$-glutamic acid and evaluation of their permeability through Caco-2 cells. Biomacromolecules. 2005;6:1104-1112.

112. Alonso-Sande M, Cuna M, Remunan-Lopez C. Formation of new glucomannan-chitosan nanoparticles and study of their ability to associate and deliver proteins. Macromolecules. 2006;39: 4152-4158.

113. Boddohi S, Moore N, Johnson PA, Kipper MJ. Polysaccharide-based polyelectrolyte complex nanoparticles from chitosan, heparin, and hyaluronan. Biomacromolecules. 2009;10:1402-1409.

114. Huang M, Vitharana SN, Peek LJ, Coop T, Berkland C. Polyelectrolyte complexes stabilize and controllably release vascular endothelial growth factor. Biomacromolecules. 2007;8:1607-1614.

115. Zhu SY, Qian F, Zhang Y, Tang C, Yin CH. Synthesis and characterization of PEG modified N-trimethylaminoethylmethacrylate chitosan nanoparticles. Eur Polym J. 2007;43:2244-2253.

116. Schatz C, Bionaz A, Lucas JM, et al. Formation of polyelectrolyte complex particles from self-complexation of $\mathrm{N}$-sulfated chitosan. Biomacromolecules. 2005;6:1642-1647.

117. Orienti I, Aiedeh K, Gianasi E, Bertasi V, Zecchi V. Indomethacin loaded chitosan microspheres. Correlation between the erosion process and release kinetics. J Microencapsul. 1996;13:463-472.

118. Bugamelli F, Raggi MA, Orienti I, Zecchi V. Controlled insulin release from chitosan microparticles. Arch Pharm (Weinheim). 1998;331: 133-138.

119. Jameela SR, Kumary TV, Lal AV, Jayakrishnan A. Progesteroneloaded chitosan microspheres: a long acting biodegradable controlled delivery system. J Control Release. 1998;52:17-24.

120. Ahmed TA, El-Say KM. Development of alginate-reinforced chitosan nanoparticles utilizing W/O nanoemulsification/internal crosslinking technique for transdermal delivery of rabeprazole. Life Sci. 2014;110: 35-43. 
121. Wang LY, Gu YH, Zhou QZ, Ma GH, Wan YH, Su ZG. Preparation and characterization of uniform-sized chitosan microspheres containing insulin by membrane emulsification and a two-step solidification process. Colloids Surf B Biointerfaces. 2006;50:126-135.

122. Wei W, Yuan L, Hu G, et al. Monodisperse chitosan microspheres with interesting structures for protein drug delivery. Adv Mater. 2008; 20:2292-2296

123. Tokumitsu H, Ichikawa H, Fukumori Y. Chitosan-gadopentetic acid complex nanoparticles for gadolinium neutron capture therapy of cancer: preparation by novel emulsion droplet coalescence technique and characterization. Pharm Res. 1999;16(12):1830-1835.

124. Chawla A, Taylor KMG, Newton JM, Johnson MCR. Production of spray dried salbutamol sulphate for use in dry powder aerosol formulations. Int J Pharm. 1994;108:233-240.

125. Gander B, Wehrli E, Alder R, Merkle HP. Quality improvement of spray-dried, protein-loaded D,L-PLA microspheres by appropriate polymer solvent selection. J Microencapsul. 1995;12:83-97.

126. Lee HK, Park JH, Kwon KC. Double-walled microparticles for single shot vaccine. J Control Release. 1997;44:283-293.

127. Bodmeier R, Chen H. Preparation of biodegradable poly $( \pm)$-lactide microspheres using a spray-drying technique. J Pharm Pharmacol. 1988;40:754-757.

128. Yang $\mathrm{M}$, Velaga $\mathrm{S}$, Yamamoto $\mathrm{H}$, et al. Characterisation of salmon calcitonin in spray-dried powder for inhalation. Effect of chitosan. Int J Pharm. 2007;331:176-181.

129. Kusonwiriyawong C, Lipipun V, Vardhanabhuti N, Zhang Q, Ritthidej GC. Spray-dried chitosan microparticles for cellular delivery of an antigenic protein: physico-chemical properties and cellular uptake by dendritic cells and macrophages. Pharm Res. 2013;30(6) 1677-1697.

130. He P, Davis SS, Illum L. Chitosan microspheres prepared by spray drying. Int J Pharm. 1999;187:53-65.

131. Shi XY, Tan TW. Preparation of chitosan/ethylcellulose complex microcapsule and its application in controlled release of vitamin D-2. Biomaterials. 2002;23:4469-4473.

132. Harsha SN, Aldhubiab BE, Nair AB, et al. Nanoparticle formulation by Büchi B-90 Nano Spray Dryer for oral mucoadhesion. Drug Des Devel Ther. 2015;9:273-282.

133. Reverchon E, Daghero J, Marrone C, Mattea M, Poletto M. Supercritical fractional extraction of fennel seed oil and essential oil: experiments and mathematical modeling. Ind Eng Chem Res. 1999;38: 3069-3075.

134. Amidi M, Pellikaan HC, de Boer AH, Crommelin DJ, Hennink WE, Jiskoot W. Preparation and physicochemical characterization of supercritically dried insulin loaded microparticles for pulmonary delivery. Eur J Pharm Biopharm. 2008;68(2):191-200.

135. de Diego YP, Pellikaan HC, Wubbolts FE, Borchard G, Witkamp GJ, Jansens PJ. Opening new operating windows for polymer and protein micronization using the PCA process. $J$ Supercrit Fluids. 2006 $36: 216-224$.

136. Okamoto H, Nishida S, Todo H, Sakakura Y, Iida K, Danjo K. Pulmonary gene delivery by chitosan-pDNA complex powder prepared by a supercritical carbon dioxide process. J Pharm Sci. 2003;92: 371-380.

137. Melo EP, Aires-Barros MR, Cabral JM. Reverse micelles and protein biotechnology. Biotechnol Annu Rev. 2001;7:87-129.

138. Krishna SA, Amareshwar P. Preparation of bovine serum albumin loaded chitosan nanoparticle using reverse micelle method. Res J Pharm Biol Chem Sci. 2011;2(3):837-846.

139. Mitra S, Gaur U, Ghosh PC, Maitra AN. Tumor targeted delivery of encapsulated dextran-doxorubicin conjugate using chitosan nanoparticles as carrier. J Control Release. 2001;74:317-323.

140. Agnihotri SA, Aminabhavi TM. Controlled release of clozapine through chitosan microparticles prepared by a novel method. J Control Release. 2004;96:245-259.

141. Garud N, Garud A. Preparation and in-vitro evaluation of metformin microspheres using non-aqueous solvent evaporation technique. Trop J Pharm Res. 2012;11(4):577-583.
142. Particle size distributions from sub-nanometer to millimeters Available from: http://www.malvern.com/en/products/measurementtype/particle-size/. Accessed December 31, 2015.

143. El-Say KM, El-Helw AM, Ahmed OAA, Hosny KM, Ahmed TA. Novel controlled release of antihypertensive drug: preparation, in-vitro and in-vivo evaluation. Afr J Pharm Pharmacol. 2013;7(25): 1744-1756.

144. Merkus HG. Particle Size Measurements: Fundamentals, Practice, Quality. New York, NY: Springer Science \& Business Media; 2009:15.

145. Ahmed TA, El-Say KM, Mahmoud MF, Samy AM, Badawi AA. Miconazole nitrate oral disintegrating tablets: in vivo performance and stability study. AAPS PharmSciTech. 2012;13(3):760-771.

146. Ma Z, Yeoh HH, Lim LY. Formulation $\mathrm{pH}$ modulates the interaction of insulin with chitosan nanoparticles. J Pharm Sci. 2002; 91(6):1396-1404.

147. Gazori T, Khoshayand MR, Azizi E, Yazdizade P, Nomani A, Haririan I. Evaluation of alginate/chitosan nanoparticles as antisense delivery vector: formulation, optimization and in vitro characterization. Carbohydr Polym. 2009;77:599-606.

148. Cover NF, Lai-Yuen S, Parsons AK, Kumar A. Synergetic effects of doxycycline-loaded chitosan nanoparticles for improving drug delivery and efficacy. Int J Nanomedicine. 2012;7:2411-2419.

149. Rodrigues S, da Costa AM, Grenha A. Chitosan/carrageenan nanoparticles: effect of cross-linking with tripolyphosphate and charge ratios. Carbohydr Polym. 2012;89(1):282-289.

150. Casettari L, Castagnino E, Stolnik S, Lewis A, Howdle SM, Illum L. Surface characterisation of bioadhesive PLGA/chitosan microparticles produced by supercritical fluid technology. Pharm Res. 2011;28(7):1668-1682.

151. Kim K, Kim JH, Park H, et al. Tumor-homing multifunctional nanoparticles for cancer theragnosis: simultaneous diagnosis, drug delivery, and therapeutic monitoring. $J$ Control Release. 2010;146(2):219-227.

152. Nishimura K, Nishimura S, Nishi N, et al. Adjuvant activity of chitin derivatives in mice and guinea pigs. Vaccine. 1985;3:379-384.

153. Nishimura K, Ishihara C, Ukei S, Tokura S, Azuma I. Stimulation of cytokine production in mice using deacetylated chitin. Vaccine. 1986;4:151-156.

154. Zaharoff DA, Rogers CJ, Hance KW, Schlom J, Greiner JW. Chitosan solution enhances the immunoadjuvant properties of GM-CSF. Vaccine. 2007;25:8673-8686.

155. Zaharoff DA, Rogers CJ, Hance KW, Schlom J, Greiner JW. Chitosan solution enhances both humoral and cell-mediated immune responses to subcutaneous vaccination. Vaccine. 2007;25:2085-2094.

156. Read RC, Naylor SC, Potter CW, et al. Effective nasal influenza vaccine delivery using chitosan. Vaccine. 2005;23:4367-4374.

157. Nagamoto T, Hattori Y, Takayama K, Maitani Y. Novel chitosan particles and chitosan-coated emulsions inducing immune response via intranasal vaccine delivery. Pharm Res. 2004;21(4):671-674.

158. Jaganathan KS, Vyas SP. Strong systemic and mucosal immune responses to surface-modified PLGA microspheres containing recombinant hepatitis B antigen administered intranasally. Vaccine. 2006; 24(19):4201-4211.

159. Zhao H, Wu B, Wu H, et al. Protective immunity in rats by intranasal immunization with Streptococcus mutans glucan-binding protein D encapsulated into chitosan-coated poly(lactic-co-glycolic acid) microspheres. Biotechnol Lett. 2006;28(16):1299-1304.

160. Amidi M, Mastrobattista E, Jiskoot W, Hennink WE. Chitosan-based delivery systems for protein therapeutics and antigens. Adv Drug Deliv Rev. 2010;62(1):59-82.

161. Jayakumar R, Chennazhi KP, Muzzarelli RAA, Tamura H, Nair SV, Selvamurugan N. Chitosan conjugated DNA nanoparticles in gene therapy. Carbohydr Polym. 2010;79(1):1-8.

162. Katas H, Alpar H. Development and characterization of chitosan nanoparticles for siRNA delivery. $J$ Control Release. 2006;115(2): 216-225.

163. Liu XD. Chitosan-siRNA complex nanoparticles for gene silencing. J Biomed Engin. 2010;27(1):97-101. 
164. Gao S, Chen J, Xu X, et al. Galactosylated low molecular weight chitosan as DNA carrier for hepatocyte-targeting. Int J Pharm. 2003; 255:57-68.

165. Dautry-Varsat A. Receptor-mediated endocytosis: the intracellular journey of transferrin and its receptor. Biochimie. 1986;68:375-381.

166. Lee D, Lockey R, Mohapatra S. Folate receptor-mediated cancer cell specific gene delivery using folic acid-conjugated oligochitosans. J Nanosci Nanotechnol. 2006;6:2860-2866.

167. Lavertu M, Methot S, Trankhanh N, Buschmann M. High efficiency gene transfer using chitosan/DNA nanoparticles with specific combinations of molecular weight and degree of deacetylation. Biomaterials. 2006;27(27):4815-4824.

168. Mansouri S, Cuie Y, Winnik F, et al. Characterization of folate chitosanDNA nanoparticles for gene therapy. Biomaterials. 2006;27(9): 2060-2065.

169. Yousefpour P, Atyabi F, Vasheghani-Farahani E, Movahedi AA, Dinarvand R. Targeted delivery of doxorubicin-utilizing chitosan nanoparticles surface-functionalized with anti-Her2 trastuzumab. Int J Nanomedicine. 2011;6:1977-1990.

170. Lin A, Chen J, Liu Y, et al. Preparation and evaluation of N-caproyl chitosan nanoparticles surface modified with glycyrrhizin for hepatocyte targeting. Drug Dev Ind Pharm. 2009;35(11):1348-1355.

171. Kim JH, Kim YS, Park K, et al. Antitumor efficacy of cisplatinloaded glycol chitosan nanoparticles in tumor-bearing mice. J Control Release. 2008;127(1):41-49.

172. Min KH, Park K, Kim YS, et al. Hydrophobically modified glycol chitosan nanoparticles-encapsulated camptothecin enhance the drug stability and tumor targeting in cancer therapy. J Control Release. 2008; 127(3):208-218.

173. Yao Q. Study on the Two-Ligand Modified Chitosan Nanoparticles Actively Targeting to Malignant Liver Cells [PhD thesis]. Chengdu, People's Republic of China: Sichuan University. Doctoral Paper of Sichuan University; 2006. Available from: http://www.globethesis. com/?t=1104360185994553. Accessed December 31, 2015.

174. Tabata Y, Ikada Y. Macrophage phagocytosis of biodegradable microspheres composed of L-lactic acid/glycolic acid homo- and copolymers. J Biomed Mater Res. 1988;22(10):837-858.

175. Tiyaboonchai W. Chitosan nanoparticles: a promising system for drug delivery. Naresuan Univ J. 2003;11(3):51-66

176. Guo S, Huang L. Nanoparticles escaping RES and endosome: challenges for siRNA delivery for cancer therapy. JNanomater. 2011;2011: $1-12$.

177. Owens D III, Peppas N. Opsonization, biodistribution, and pharmacokinetics of polymeric nanoparticles. Int J Pharm. 2006;307(1): 93-102.

178. Patel K, Shrimanker M, Dave R, Modi H, Anand J, Bhadani S. Preparation and in vivo study of doxorubicin $\mathrm{HCl}$ loaded chitosan nanoparticles prepared by W/O emulsion method. Int J Curr Res. 2012;4(12):438-440.

179. Huo M, Zhang Y, Zhou J, et al. Synthesis and characterization of lowtoxic amphiphilic chitosan derivatives and their application as micelle carrier for antitumor drug. Int J Pharm . 2010;394(1-2):162-173.

180. Ashford M. Biopharmaceutical principles of drug delivery. In: Aulton ME, editor. Pharmaceutics: The Science of Dosage Form Design. 2nd ed. New York, NY: Churchill Livingstone; 2001:211-253.

181. Chang $\mathrm{CH}$, Lin YH, Yeh CL, et al. Nanoparticles incorporated in $\mathrm{pH}$-sensitive hydrogels as amoxicillin delivery for eradication of Helicobacter pylori. Biomacromolecules. 2010;11(1):133-142.

182. Gisbert JP, Torrado G, Torrado S, Olivares D, Pajares JM. Clinical trial evaluating amoxicillin and clarithromycin hydrogels (chitosanpolyacrylic acid polyionic complex) for $\mathrm{H}$. pylori eradication. J Clin Gastroenterol. 2006;40(7):618-622.

183. Dhaliwal S, Jain S, Singh HP, Tiwary AK. Mucoadhesive microspheres for gastroretentive delivery of acyclovir: in vitro and in vivo evaluation. AAPS J. 2008;10(2):322-330.

184. Wei W, Ma GH, Wang LY, Wu J, Su ZG. Hollow quaternized chitosan microspheres increase the therapeutic effect of orally administered insulin. Acta Biomater. 2010;6(1):205-209.
185. Hejazi R, Amiji M. Chitosan-based gastrointestinal delivery systems. J Control Release. 2003;89:151-165.

186. Varshosaz J, Jaffarian Dehkordi A, Golafshan S. Colon-specific delivery of mesalazine chitosan microspheres. J Microencapsul. 2006; 23:329-339.

187. Mladenovska K, Raicki RS, Janevik EI, et al. Colon-specific delivery of 5-aminosalicylic acid from chitosan-Ca-alginate microparticles. Int J Pharm. 2007;342(1-2):124-136.

188. Oosegi T, Onishi H, Machida Y. Novel preparation of enteric-coated chitosan-prednisolone conjugate microspheres and in vitro evaluation of their potential as a colonic delivery system. Eur J Pharm Biopharm. 2008;68:260-266.

189. Jain SK, Jain A, Gupta Y, Ahirwar M. Design and development of hydrogel beads for targeted drug delivery to the colon. AAPS PharmSciTech. 2007;8:E56.

190. Elzatahry AA, Eldin MSM. Preparation and characterization of metronidazole loaded chitosan nanoparticles for drug delivery application. Polym Adv Technol. 2008;19:1787-1791.

191. Kublik H, Vidgren MT. Nasal delivery systems and their effect on deposition and absorption. Adv Drug Deliv Rev. 1998;29: $157-177$.

192. Costantino HR, Illum L, Brandt G, Johnson PH, Quay SC. Intranasal delivery: physicochemical and therapeutic aspects. Int J Pharm. 2007;337:1-24.

193. Baig AM, Khan NA. Novel chemotherapeutic strategies in the management of primary amoebic meningoencephalitis due to Naegleria fowleri. CNS Neurosci Ther. 2014;20(3):289-290.

194. McMartin C, Hutchinson LE, Hyde R, Peters GE. Analysis of structural requirements for the absorption of drugs and macromolecules from the nasal cavity. J Pharm Sci. 1987;76:535-540.

195. Varshosaz J, Sadrai H, Alinagari R. Nasal delivery of insulin using chitosan microspheres. J Microencapsul. 2004;21:761-774.

196. Fernandez-Urrusuno R, Romani D, Calvo P, Vila-Jato JL, Alonso MJ. Development of a freeze-dried formulation of insulin-loaded chitosan nanoparticles intended for nasal administration. STP Pharma Sci. 1999; 9:429-436.

197. Jiang HL, Kang ML, Quan JS, et al. The potential of mannosylated chitosan microspheres to target macrophage mannose receptors in an adjuvant-delivery system for intranasal immunization. Biomaterials. 2008;29(12):1931-1939.

198. Kang ML, Jiang HL, Kang SG, et al. Pluronic F127 enhances the effect as an adjuvant of chitosan microspheres in the intranasal delivery of Bordetella bronchiseptica antigens containing dermonecrotoxin. Vaccine. 2007;25(23):4602-4610.

199. Holmgren J, Czerkinsky C. Mucosal immunity and vaccines. Nat Med. 2005;11(4):S45-S53.

200. de la Fuente M, Raviña M, Paolicelli P, Sanchez A, Seijo B, Alonso MJ. Chitosan-based nanostructures: a delivery platform for ocular therapeutics. Adv Drug Deliv Rev. 2010;62(1):100-117.

201. De Campos AM, Sanchez A, Alonso MJ. Chitosan nanoparticles: a new vehicle for the improvement of the delivery of drugs to the ocular surface. Application to cyclosporin A. Int J Pharm. 2001;224 (1-2): $159-168$.

202. Wadhwa S, Paliwal R, Paliwal SR, Vyas SP. Hyaluronic acid modified chitosan nanoparticles for effective management of glaucoma: development, characterization, and evaluation. J Drug Target. 2010; 18(4):292-302.

203. Puras G, Zarate J, Aceves M, et al. Low molecular weight oligochitosans for non-viral retinal gene therapy. Eur J Pharm Biopharm. 2013; 83(2):131-140.

204. Klausner EA, Zhang Z, Chapman RL, Multack RF, Volin MV. Ultrapure chitosan oligomers as carriers for corneal gene transfer. Biomaterials. 2010;31(7):1814-1820.

205. de la Fuente M, Seijo B, Alonso MJ. Bioadhesive hyaluronan-chitosan nanoparticles can transport genes across the ocular mucosa and transfect ocular tissue. Gene Ther. 2008;15(9):668-676.

206. Groneberg DA, Witt C, Wagner U, Chung KF, Fischer A. Fundamentals of pulmonary drug delivery. Respir Med. 2003;97:382-387. 
207. Patil JS, Sarasija S. Pulmonary drug delivery strategies: a concise, systematic review. Lung India. 2012;29(1):44-49.

208. Evans CM, Koo JS. Airway mucus: the good, the bad, the sticky. Pharmacol Ther. 2009;121:332-348.

209. Palecanda A, Kobzik L. Receptors for unopsonized particles: the role of alveolarmacrophages scavenger receptors. Curr Mol Med. 2001;1: 589-595.

210. Chono S, Tanino T, Seki T, Morimoto K. Influence of particle size on drug delivery to rat alveolar macrophages following pulmonary administration of ciprofloxacin incorporated into liposomes. J Drug Target. 2006; 14:557-566.

211. Ferin J, Oberdorster G, Soderholm SC, Gelein R. Pulmonary tissue access of ultrafine particles. J Aerosol Med. 1991;4:57-68.

212. Grenha A, Remunan-Lopez C, Carvalho EL, Seijo B. Microspheres containing lipid/chitosan nanoparticles complexes for pulmonary delivery of therapeutic proteins. Eur J Pharm Biopharm. 2008;69(1): 83-93.

213. Sung JC, Padilla DJ, Garcia-Contreras L, et al. Formulation and pharmacokinetics of self-assembled rifampicin nanoparticle systems for pulmonary delivery. Pharm Res. 2009;26(8):1847-1855.

214. Bharatwaj B, Wu L, Whittum-Hudson JA, da Rocha SR. The potential for the noninvasive delivery of polymeric nanocarriers using propellant-based inhalers in the treatment of Chlamydial respiratory infections. Biomaterials. 2010;31(28):7376-7385.

215. Grenha A, Grainger CI, Dailey LA, et al. Chitosan nanoparticles are compatible with respiratory epithelial cells in vitro. Eur J Pharm Sci. 2007;31(2):73-84.

216. Huang YC, Vieira A, Huang KL, Yeh MK, Chiang CH. Pulmonary inflammation caused by chitosan microparticles. J Biomed Mater Res A. 2005;75(2):283-287.

217. Choi M, Cho M, Han BS, et al. Chitosan nanoparticles show rapid extrapulmonary tissue distribution and excretion with mild pulmonary inflammation to mice. Toxicol Lett. 2010;199(2):144-152.

218. Rodrigues S, Cordeiro C, Seijo B, Remunán-López C, Grenha A. Hybrid nanosystems based on natural polymers as protein carriers for respiratory delivery: stability and toxicological evaluation. Carbohydr Polym. 2015;123:369-380.

219. Paudel KS, Milewski M, Swadley CL, Brogden NK, Ghosh P, Stinchcomb AL. Challenges and opportunities in dermal/transdermal delivery. Ther Deliv. 2010;1:109-131.
220. Bos JD, Meinardi MM. The 500 Dalton rule for the skin penetration of chemical compounds and drugs. Exp Dermatol. 2000;9:165-169.

221. Kim DG, Jeong YI, Choi C, et al. Retinol-encapsulated low molecular water-soluble chitosan nanoparticles. Int J Pharm. 2006;319: 130-138.

222. Hasanovic A,Zehl M, Reznicek G, Valenta C. Chitosan-tripolyphosphate nanoparticles as a possible skin drug delivery system for aciclovir with enhanced stability. J Pharm Pharmacol. 2009;61:1609-1616.

223. Ozbas-Turan S, Akbuga J, Sezer AD. Topical application of antisense oligonucleotide-loaded chitosan nanoparticles to rats. Oligonucleotides. 2010;20:147-153.

224. Ozbas-Turan S, Akbuga J. Plasmid DNA-loaded chitosan/TPP nanoparticles for topical gene delivery. Drug Deliv. 2011;18:215-222.

225. Usman MS, El Zowalaty ME, Shameli K, Zainuddin N, Salama M, Ibrahim NA. Synthesis, characterization, and antimicrobial properties of copper nanoparticles. Int J Nanomedicine. 2013;8:4467-4479.

226. Sanpui P, Murugadoss A, Durga Prasad PV, Ghosh SS, Chattopadhyaya A. The antibacterial properties of a novel chitosan-Ag nanoparticle composite. Int J Food Microbiol. 2008;124:142-146.

227. Honary S, Ghajar K, Khazaeli P, Shalchian P. Preparation, characterization and antibacterial properties of silver-chitosan nanocomposites using different molecular weight grades of chitosan. Trop J Pharm Res. 2011;10(1):69.

228. Bhumkar DR, Joshi HM, Sastry M, Pokharkar VB. Chitosan reduced gold nanoparticles as novel carriers for transmucosal delivery of insulin. Pharm Res. 2007;24(8):1415-1426.

229. Salehizadeh H, Hekmatian E, Sadeghi M, Kennedy K. Synthesis and characterization of core-shell $\mathrm{Fe}_{3} \mathrm{O}_{4}$-gold-chitosan nanostructure. J Nanobiotechnology. 2012;10:3. doi:10.1186/1477-3155-10-3.

230. Qi L, Xu Z, Jiang X, Hu C, Zou X. Preparation and antibacterial activity of chitosan nanoparticles. Carbohydr Res. 2004;339(16): 2693-2700

231. Tokarek K, Hueso JL, Kuśtrowski P, Stochel G, Kyzioł A. Green synthesis of chitosan-stabilized copper nanoparticles. Eur J Inorg Chem. 2013;2013(28):4940-4947.

232. Chattopadhyay S, Dash SK, Kar Mahapatra S, et al. Chitosan-modified cobalt oxide nanoparticles stimulate TNF- $\alpha$-mediated apoptosis in human leukemic cells. J Biol Inorg Chem. 2014;19(3):399-414.
Drug Design, Development and Therapy

\section{Publish your work in this journal}

Drug Design, Development and Therapy is an international, peerreviewed open-access journal that spans the spectrum of drug design and development through to clinical applications. Clinical outcomes, patient safety, and programs for the development and effective, safe, and sustained use of medicines are a feature of the journal, which

\section{Dovepress}

has also been accepted for indexing on PubMed Central. The manuscript management system is completely online and includes a very quick and fair peer-review system, which is all easy to use. Visit http://www.dovepress.com/testimonials.php to read real quotes from published authors. 